\title{
CSAE WPS/2007-17
}

\section{Risk Sharing, Commitment and Information: An experimental analysis.}

\author{
Abigail Barr \\ Centre for the Study of African Economies, Oxford University \\ Garance Genicot \\ Georgetown University
}

August 2007.

\begin{abstract}
This paper describes and analyzes the results of a unique field experiment especially designed to test the effects of the level of commitment and information available to individuals when sharing risk. We find that limiting exogenously provided commitment is associated with less risk sharing, while limiting information on defections can be associated with more risk sharing. These results can be understood by distinguishing between intrinsic and extrinsic incentives, and by recognizing that social sanctions are costly to inflict or that individuals suffer from time-inconsistent preferences. Comparing the groups formed within our experiment with the real life risk sharing networks in a few villages allows us to test the external validity of our experiment and suggests that the results are salient to our understanding of risk sharing arrangements observed in developing countries.
\end{abstract}

JEL Classification Numbers: C93; D71; D81; O12.

Key Words: Field experiment; risk sharing; social sanctions; insurance; limited commitment; asymmetry of information.

We are grateful for comments by seminar participants at the Centre for the Study of African Economies at Oxford University, the DRG at the World Bank, the University College London, Sussex University, Boston University and the NEUDC. We also thank the editor and three anonymous referees for useful comments on an earlier draft. Barr's research was funded by the Department for International Development under ESCOR grant number R7650. Genicot is also grateful to MIT for their hospitality during the preparation of the current version. Please address all correspondence to Abigail.Barr@economics.ox.ac.uk and gg58@georgetown. edu. 


\section{INTRODUCTION}

Over four fifths of the world's population do not have access to formal insurance against income and consumption shocks (Holtzmann, Packard, and Cuesta, (2000)). In response to the large fluctuations in their income, people often rely on informal loans and transfers to smooth consumption. Efficiency would require that individuals be insured against all idiosyncratic shocks. Within a community, this means that variations in an individual's consumption should be fully explained by variations in aggregate income, and not by individual income shocks. This prediction has been the foundation for most of the empirical tests of risk-sharing in the literature. From these empirical studies we have learnt that full risk pooling is rare (e.g., Ravallion and Dearden (1988), Morduch (1991), Ravallion and Chaudhuri (1991), Alderman and Paxson (1992), Townsend (1994)), that some types of shocks are more likely to be informally insured than others, that risk pooling is associated with certain types of relationship (e.g., Grimard (1997), De Weerdt (2002), Fafchamps and Lund (2003), Dekker (2003)), and that allowing for history dependence in a model of risk-sharing without commitment better fits the data (Ligon, Thomas and Worrall (2002)).

Informal risk-sharing arrangements are potentially limited by the presence of various incentive constraints, with asymmetries in information and the lack of commitment - the fact that these arrangements have to be self-enforcing - receiving particular attention. A recent and growing theoretical literature investigates in detail how these factors constrain the risk sharing arrangements that people can engage in (e.g., Coate and Ravallion (1993), Fafchamps (1998), Kocherlakota (1996), Genicot and Ray (2002), Ligon (1998)). However, few empirical studies have aimed to directly identify the effect of such factors on the efficiency of the risk sharing arrangements that people enter into. The difficulty lies in measuring the possible asymmetries of information and the extent of commitment available to individuals.

Moreover, following Platteau (1994a, 1994b), Fafchamps (1992, 1996), Posner and Rasmusen (1999), Kreps (1997) and others, it is important to acknowledge that both extrinsic incentives, especially sanctions that can credibly be threatened, and intrinsic motivations, such as altruism, inequality aversion and reciprocal kindness, can act as bases for commitment. Kinship, co-ethnicity, shared clan membership, and religious co-affiliation are all statistically associated with flows of assistance (Grimard (1997), De Weerdt (2002), Fafchamps and Lund (2003), Dekker (2003)), but is this because such relationships facilitate the effective use of extrinsic incentives (via greater observability, for example) or because they are associated with relationship-specific forms of intrinsic motivation? Surprisingly little attention has been paid to the distinction between intrinsic motivations and extrinsic incentives in the risk sharing literature. A notable exception being Foster and Rosenzweig 
(2001) who show that altruism could actually reduce transfers in the presence of limited commitment. This result and the growing experimental evidence that extrinsic incentives can crowd out intrinsic motivations and thereby reduce rather than increase cooperation (Cardenas, Stranlund, and Willis (2000), Bohnet, Frey, and Huck (2001)) highlight the importance of distinguishing between the two.

This paper describes and analyzes the results of a unique field experiment especially designed to test the effects of changes in the level of commitment and information available to individuals when entering into risk sharing arrangements. The experiment was run in a number of Zimbabwean villages, the inhabitants of which are known to engage in risk sharing arrangements in real life. Within the experiment, subjects were asked to take part in a gambling game and invited to form risk sharing groups that pool and share the gains from their gambles under three treatments that varied with respect to the level of exogenous commitment - the ease with which individuals could opt out of their group or "defect" after learning the realization of their own gamble - and whether information on such defections was public or private. We find that: (1) when full commitment is exogeneously provided, individuals engage in substantial risk sharing and make choices that are more risky and more profitable than when this exogenous commitment is limited; and (2) under limited exogenous commitment, less risk sharing occurs when defections are public than when they are private. Result (1) suggests that exogenous source of commitment is valuable to these villagers, which in turn implies that their intrinsic motivations and the commitment they can maintain through social sanctioning are not sufficient to guarantee full risk sharing. Result (2) seems at first counter-intuitive. That the level of information on defections revealed in the game affects risk sharing suggests that social sanctions matter. However, we would have expected that more information on defections would result in greater sanctioning possibilities and hence more rather than less risk sharing. We provide two possible explanations for this result. If punishment is costly, it is possible that, although defections are less likely when they must be executed publicly, individuals will choose not to participate in risk sharing groups in order to avoid such costs. Alternatively, individuals might worry about being tempted to defect and attract public sanctions and shame when defection is public. If they prefer not to be tempted and sanctioned ex-ante or know they will suffer regret if they are, they may choose not to engage in risk sharing arrangements. These mechanisms are explained in detail in Section 4.

Our results may also be relevant for the growing experimental literature on punishment and social sanctions in public good games. Rege and Telle (2004), for instance, find that contributions to the public good increased significantly when subjects contribute publicly as opposed to anonymously. However, in most public good games groups and the availability of sanctions are given. But, when subjects 
vote on the possibility of sanctions or rewards, Sutter, Haigner and Kocher (2007) find that subjects prefer the latter even when the former would be more effective.

We find that a framed field experiment played face-to-face by fellow villagers in contrast with anonymous laboratory-based experiments - is particularly well suited to our purpose. ${ }^{1}$ First, we are interested in observing villagers decisionmaking behaviour in a context that is sufficiently close to real life so as to be recognisable to them. ${ }^{2}$ Second, our field experiment imposed enough control to allow us to exogenously influence the two environmental factors of interest, commitment and information on defections, and create measures of risk sharing and risk taking needed for the analysis, while leaving the villagers as free as possible to make decisions based on the considerations they might usually take into account. Hence, from their behavior in the experiment, we learn about the characteristics of their environment and the risk sharing arrangements that they make in real life. Finally, it allows us to compare, for a subset of villages, the risk sharing groups formed within the context of the experiment with risk sharing networks in real life. Using a non-parametric procedure, we show that in four out of the five villages the experimental and real risk sharing networks were significantly related. This gives us some confidence in the external validity of the experiment.

The remainder of this paper is organized as follows: Section 2 provides a detailed description of the experimental design. Section 3 presents a stylized model of the experiment. Section 4 then presents the analysis of the data and Section 5 expands on the possible explanations for our results. A description of the data used to investigate the external validity of the experiment and the results of the test are presented in Section 6. Finally, Section 7 concludes.

\section{Experimental Design}

The following experiment was designed to examine how different levels of commitment and information affect risk-sharing and risk-taking. Subjects participate in two rounds of an experiment separated by one day. During Round 1, subjects play individually. Each subject is called separately and asked to choose one out of six gambles that vary in average return and riskiness. Each earns the realized gain from the chosen gamble. In Round 2, individuals are again called separately one by one and offered the same choice of gambles. However, prior to choosing and

\footnotetext{
${ }^{1}$ According to Harrison and List (2004), our experiment is 'framed' because the villagers were required to make decisions about whether and how to interact not with anonymous others but face-to-face with their fellow villagers. And, this being the case, information gleaned during their everyday lives would have been relevant to their decisions.

${ }^{2}$ Post play discussions indicated that the villagers saw the parallels between the game and aspects of their everyday lives choosing crops with different yields and levels of risk, helping each other out if and when crop choices proved erroneous.
} 
depending on the treatment being applied to their village, subjects are given the option of forming risk sharing groups. Each participating village was randomly selected into either a control sample or one of three treatment samples. Under the control, C, subjects play individually again: their Round 2 is identical to their Round 1. In contrast, under the first treatment, Treatment $1(T 1)$, the villagers are invited to form risk sharing groups with full commitment. Villagers under Treatment 2 (T2) and Treatment 3 (T3) can also form risk sharing groups, but with limited commitment: in both cases, subjects can if they wish opt out of their groups after learning the outcome of their gambles. The information on such defections is public in $T 3$ and private in T2. Notice that in none of the treatments do subjects observe each other's choice of gamble or outcome.

Below, we describe these decision making environments, i.e., the choice of gambles and the risk-sharing technologies under each treatment, in more detail. However, first, we introduce our experimental subjects.

The subjects. Our experiment involved over 600 inhabitants from 23 Zimbabwean villages located in three different areas of the country. Some of these villages were formed in the $80 \mathrm{~s}$ as a result of land redistribution. The inhabitants of these resettled villages are less likely to be related to each other by blood. However, their villages tend to be geographically denser and have been shown to engage in more associational activity (see Barr 2004). For these reasons, we will control for the type of village in the analysis.

The day before the experiment started in each of the selected villages, each household was visited and invited to send an adult of a specific gender to be a subject in our experiment. Whether a man or a woman was requested was randomly determined, although if none of the specified gender was present, the other was acceptable. They were told that, preferably, their representative would be either the household head or their spouse as these are the principle decision-makers in the households.

On the next day, the subjects were called to a meeting, having been told that this was to be the first of two meetings to be held on consecutive days. Once the research team had been introduced, each subject met one of four research assistants (RAs) in private. They were taught the gamble choice game (described next), their comprehension was tested, and then they played. After being paid, they were asked to sit separately from those who had not yet played to await further instructions. Tea and snacks were served. Once everyone had played Round 1, Round 2 of the experiment - to be played on the next day - was explained. They were told that they would play the gamble choice game again and, depending on their treatment category, the rules relating to the risk sharing groups that they could form. 
In total, 640 subjects attended Round 1 of the experiment in their village. Of these, 22 did not show up for Round 2 because they had been called away on unforeseen business. Each of these sent another member of their household in their stead. The absentees were more likely to be household heads and were also older and more likely to be male as a result. ${ }^{3}$ Since household headship is not found to be significant in any of our analyses, any sample attrition bias is likely to be insignificant.

In addition, to the replacements, two households sent representatives to Round 2 who had not sent anyone to Round 1. Thus, a total of 664 subjects were involved in the experiment, although only 642 took part in the more interesting Round 2 and only 618 took part in both Round 1 and Round 2 .

Table 1 presents some descriptive statistics on the subjects. In Round 2, fortyeight percent of our subjects were female, 69 percent were married, 40 percent were heads of households. The average age was 42 years and, on average, they had 7 years of education. Eighty-three percent lived in resettled villages and the samples from each of the three areas were similar in size.

To look at the representativeness of our sample, in Table 1, we compare the mean characteristics of the experimental subjects with those of the adult (over 15 year old) population in the same villages as indicated by a survey that took place earlier in the same year. Given our recruitment strategy, it is not surprising that household heads and their spouses are overrepresented in our sample. This also explains why our subjects are older and more likely to be married. Women are slightly underrepresented, despite our efforts to ensure a 50:50 split. We think this is because the recruiting RA mentioned that money could be won and this gave the household heads an incentive to turn up at the games themselves.

The gamble choice. The gamble choice game that individuals play in both rounds of the experiment goes as follows. Each subject $i$ is called to a private meeting with an RA and asked to choose one gamble $\ell_{i}$ out of six gambles offered $\mathcal{L} \equiv$ $\{A, B, \ldots F\}$. Every gamble $\ell \in \mathcal{L}$ yields either a high payoff $\bar{y}_{\ell}$ or low payoff $\underline{y}_{\ell}$ each with probability 0.5 . Whichever gamble was chosen, the payoff was determined by playing a game that involved guessing which of the RA's hands contained a blue rather than a yellow counter. We denote as $y_{i}\left(\ell_{i}\right) i$ 's realized gamble gain. If the subject found the blue counter she received the high payoff associated with the gamble of her choice, $\bar{y}_{\ell_{i}}$. If she found the yellow counter, she received the low payoff associated with that gamble, $\underline{y}_{i}$.

The six gambles (taken from Binswanger (1980)) are presented in Figure 1, the chart used to present the gambles to the subjects, many of whom were illiterate.

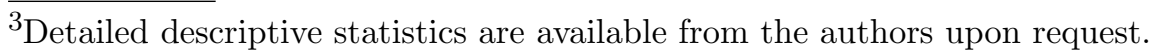


Each gamble $\ell \in\{A, B, \ldots F\}$ is depicted as two piles of money, the high payoff $\left(\bar{y}_{\ell}\right)$ on a blue background and the low payoff $\left(\underline{y}_{\ell}\right)$ on a yellow background.

Table 2 presents the expected returns on each gamble, which vary from 100 to 200 Zimbabwean dollars, and their variances, which lie between 0 and 200 Zimbabwean dollars. At the time of the experiment, one day of casual labour would have earned a villager approximately 200 Zimbabwean dollars, moreover such work opportunities were scarce. ${ }^{4}$ Hence, the stakes are substantial and it is reasonable to expect individuals to exhibit risk aversion. ${ }^{5}$

Finally, Table 2 presents the intervals of constant relative risk aversion implied by an individual choosing each of the six gambles offered and whose only source of consumption expenditure is the gamble payoff.

The Treatments. After all the villagers had played Round 1 of the gamble choice game, they were given detailed verbal instructions regarding Round 2 , to be played on the following day, and provided with copies of Figure 1 to aid any discussions they wished to hold. Round 2 of the experiment differed across villages depending on their treatment category.

Control. In three randomly selected villages, the subjects were told that during the meeting scheduled for the next day, they would be playing the same game once again. This serves as a control, referred to as $C$ below.

In all other villages, people were given the option of forming 'sharing groups' before taking part in Round 2 of the gamble choice game. That is, in each village $I$ of $n$ inhabitants, the latter could partition themselves into sharing groups $S_{1}, \ldots S_{m}$ of any size (including singletons). These groups had to be exhaustive and mutually exclusive $\cup_{j=1, . . m} S_{j}=I$ and $S_{j} \cap S_{k}=0$ for $k \neq j$. The extent to which commitment to the sharing group was exogenously enforced and information relating to defections made public varied by treatment.

TREATMEnT 1. In eight randomly selected villages, Treatment 1 - referred to as T1 below - provided the subjects with a risk sharing technology exhibiting full commitment. Within a sharing group, all individual winnings from the Round 2 gamble choice game were automatically pooled and divided equally among the group's members. Hence, a subject $i$ in group $S$ of size $s$ earns a payoff $\frac{\sum_{j \in S} y_{j}\left(\ell_{j}\right)}{s}$.

\footnotetext{
${ }^{4}$ During the experiment, the average earnings were 158 and 172 Zimbabwean dollars in Rounds 1 and 2 respectively. At the time of the experiment, the official exchange rate was around 55 Zimbabwean dollars to one US dollar and, according to data collected by the researchers, the parallel market rate was approximately 2.5 times the official rate.

${ }^{5}$ See Rabin (2000) for why expected utility implies that individuals should not reveal their risk aversion when stakes are small relative to their average consumption.
} 
These rules and the monetary implications of sharing-group-formation were explained to the villagers with the aid of simple examples.

In contrast to T1, in Treatment 2 and Treatment 3 the degree of exogenous commitment inherent in the rules of the game was limited.

TREATMENT 2. In six villages (randomly selected), having been told that they could form sharing groups, the subjects were told that they could, if they wished opt out of their sharing groups in secret. They could decide whether to stay or to opt out after learning the outcome of their own gamble (but without knowing the choice or outcome of others' gambles) and while alone with an RA. Subjects who defected in this way received the gain from their own gamble as their payoff, while the rest of the gains within the group were pooled and divided equally between the remaining group members. Under this treatment, $T 2$ below, commitment was limited and information was asymmetric. Subjects may have been able to draw some inferences about defections. However, ex-post, subjects could never have been certain that someone had opted out and, in groups of three or more, about whom to suspect of foul play. ${ }^{6}$

Treatment 3. Finally, in the remaining six villages, the subjects were told that they could publicly opt out of their sharing groups. After learning the realization of their own gamble, when alone with an RA, they could decide to opt out of their sharing group but only if they were prepared to confirm their defection publicly in front of all the villagers present at the experimental session once everyone had completed their Round 2 gamble choice game. Under this treatment, T3 below, commitment is limited but there is no asymmetry of information regarding the defections.

The second round payoffs to any treatment can be represented as follows. For all subjects $i=1, . . n$, let $d_{i}$ be an indicator that takes the value 1 if $i$ stays in the group she joined and 0 if she defects. For subjects under $C$ and $T 1$ as well as singletons, we take this indicator to be 1 . A subject $i$ in group $S$ earns a payoff

$$
e_{i}=\left\{\begin{array}{c}
\frac{\sum_{j \in S} y_{j}\left(\ell_{j}\right) d_{j}}{\sum_{j \in S} d_{j}} \\
y_{i}\left(\ell_{i}\right)
\end{array} \quad \text { if } \quad \begin{array}{c}
d_{i}=1 \\
d_{i}=0
\end{array}\right.
$$

Measures of risk sharing and risk taking. In our analysis, we focus on three measures of the amount of risk sharing and risk taking that the subjects undertook during the experiment. The first is whether the subjects joined a risk sharing group, the second is the size of the risk sharing group they joined, and the third is the riskiness of their choice of gamble in Round 2. Ceteris paribus, if the members of

\footnotetext{
${ }^{6}$ Consider a group of 2 for instance. A subject whose payoff is different from her gamble gain would be sure that the other stayed. However, if a subject's payoff equals her gamble gain, it is possible that the other opted out or that he picked the same gamble and had the same outcome.
} 
a sharing group select riskier gambles, they can be said to be pooling more risk in order to secure a higher expected return. By comparing these three measures across treatments we can investigate the effects of limited commitment and asymmetric information on risk pooling.

\section{MODEL}

In this section, we present a stylized model of the experiment that will help us interpret the results. Some readers may prefer to skip this section and return to it after reading Section 4 which describes the results of the experiment.

We can distinguish between three possible sources of commitment, two relating to extrinsic incentives and one to intrinsic motivations. First, there is the exogenous extrinsic commitment technology provided by the game. This exogenous commitment is full under $T 1$ and limited under $T 2$ and $T 3{ }^{7}$ Second, there is endogenous extrinsic commitment which relates to the punishments or social sanctions that others might inflict on group members who defect by opting out of their group (for instance, excluding the culprit from social or economic interactions). ${ }^{8}$ Below, $f_{i}$ denotes the total value of these punishments to the punished individual $i$. This includes the value of any current punishment as well as any difference in $i$ 's future utility due to retaliation. We denote by $c_{j, S}$ the cost to $j$ of punishing a set of individuals $S$. Finally, as emphasized in the experimental literature, intrinsic motivations such as guilt, altruism, inequality aversion and reciprocal kindness, can act as bases for commitment. To capture intrinsic motivations in a simple way, we shall denote the loss of utility that $i$ would feel, due to such motivations, if she defects on a group $S$ of fellow villagers as $g_{i, S}$. These last two sources of commitment could sustain a substantial level of risk sharing under $T 2$ and $T 3$, although clearly the potential for social sanctions is greater under $T 3$ where information on defections is public.

Let $\nu_{i}(S)$ be the utility that $i$ expects from being in a group $S$, given her beliefs over what will happen and the characteristics of the other group members. Irrespective of the process of group formation in the villages under treatments $T 1$ to T3, stability requires the following: there should be no individual $i$ belonging to

\footnotetext{
${ }^{7}$ Subjects can opt out from their groups but, in contrast with the models of risk sharing with no commitment, group members do not observe the outcome of others' gambles prior to deciding whether to opt out and, if they stay in the group, the payoffs from the gambles are split equally. ${ }^{8}$ In experiments, Falk, Fehr, and Fischbacher (2000), Bowles, Carpenter and Gintis (2001), Masclet, Noussair, Tucker and Villeval (2003), and Carpenter and Seki (2004) for instance show that social or shame-based sanctions can be used to enhance commitment and that such sanctions are commonly threatened and applied.
} 
group $S$, while there exists another group $S^{\prime}$ such that

$$
\nu_{i}\left(S^{\prime}+i\right)>\nu_{i}(S) \text {, }
$$

and

$$
\nu_{j}\left(S^{\prime}+i\right) \geq \nu_{j}\left(S^{\prime}\right) \text { for all } S^{\prime} \neq \emptyset, j \in S^{\prime} .
$$

In particular, this implies that the individual participation constraints must be satisfied, i.e. group members must prefer being in a group than on their own.

Control. Under $C$, subjects participate in the Round 2 gamble choice game individually. Their only decision concerns their choice of gamble, and they get the following expected utility:

$$
\nu_{i}^{C}(i) \equiv \nu_{i}=\arg \max _{\ell \in \mathcal{L}} \frac{1}{2}\left(u_{i}\left(\underline{y}_{\ell_{i}}\right)+u_{i}\left(\bar{y}_{\ell_{i}}\right)\right) .
$$

Treatment 1. Under $T 1$, subjects can form sharing groups with full exogenous commitment. The choice of gamble for the members of a given group should now be an equilibrium. Consider a group $S$ of size $s$. We denote by $\boldsymbol{\sigma}_{i}$ a strategy for $i$, where $\sigma_{i}(\ell) \in[0,1]$ is the probability that $i$ chooses gamble $\ell$ and $\sum_{\ell} \sigma_{i}^{*}(\ell)=1$, and $\Sigma$ is the set of possible strategies. Given $\boldsymbol{\sigma}, i$ 's expected utility is

$$
U_{i}(\boldsymbol{\sigma}, S)=E_{\boldsymbol{\sigma}} u_{i}\left(\frac{1}{s} \sum_{j \in S} y_{j}\left(\ell_{j}\right)\right)
$$

where $E_{\boldsymbol{\sigma}}$ represents the expectation on the gamble gain given the strategies. For $\boldsymbol{\sigma}^{*}(S) \equiv\left\{\boldsymbol{\sigma}_{i}^{*}(S)\right\}_{\forall i \in S}$ to be an equilibrium, it must be that for all $i \in S$,

$$
\boldsymbol{\sigma}_{i}^{*}=\arg \max _{\boldsymbol{\sigma}_{i} \in \Sigma} U_{i}\left(\boldsymbol{\sigma}_{-i}^{*}, \boldsymbol{\sigma}_{i}, S\right) .
$$

In an equilibrium $\boldsymbol{\sigma}^{*}, i$ 's expected utility is

$$
\nu_{i}^{T 1}(S)=U_{i}\left(\boldsymbol{\sigma}^{*}, S\right)
$$

This formulation is based on two implicit assumptions. First, group members do not coordinate their gamble choices and so neither suffer nor expect to suffer any punishment for their choice of gamble. And second, other group members' preferences, in particular with respect to risk, are fully known. ${ }^{9}$

Under this treatment group formation has two interesting effects on the choice of gamble. First, the riskiness of the gambles chosen by different members of the same group may be strategically complementary and so multiple equilibria may exist. Second, on average, we expect the subjects in any one group to select more risky gambles than they would alone. However, this does not need to be the case at the

9It would be easy to relax this assumption and include some uncertainty with respect to others' choice of gamble. 
individual level. Indeed, in equilibrium, a risk averse group member who suspects that other members will pick very risky gambles may select a safer gamble than he would if playing alone. Finally, note that heterogeneous individuals would not necessarily form the largest group possible. This is due to expected differences in their preferred gambles. For instance, a subject with very low risk aversion may not want to be in a group with a highly risk averse subject who would choose a safe gamble with low expected return.

Treatment 2. Under this treatment, subjects can secretly opt out of their sharing groups after learning the outcome of their gambles. Defectors receive the gain from their own gamble as their earnings, while the remaining group members share the sum of their gains equally. The latter may be able to draw some inferences about the likelihood that someone has defected from their earnings. However, they cannot infer with certainty that a defection has occurred, and cannot identify a specific defector in groups of three or more. Subjects who defect do not learn anything from their earnings. Moreover, other villagers would not know of the defection. Hence, under this treatment, there is very little extrinsic commitment, either exogenous or endogenous: defections are allowed and the likelihood of detection and punishment is limited. Punishments could be imposed based on inferred likelihoods of defection. However, we make the simplifying assumption that this does not occur. ${ }^{10}$ So, under T3 we assume that only intrinsic motivations prevent subjects who win their gambles from opting out of their sharing groups.

Consider a group $S$. Let $e_{i}$ represent $i$ 's realized earnings at the end of the game if she stays in the group and let $\mathcal{E}$ be the set of possible values for $e_{i}$ : the set of averages of all possible subsets of $\mathbf{y}$ for all possible realizations of $\mathbf{y}$. For all $e \in \mathcal{E}$, we denote as $\pi_{i}\left(e \mid y_{i}, S\right)$ the probability that individual $i$ assigns, given her realized gamble gain $y_{i}$, to earning $e$ if she stays in the group. These probabilities reflect individual $i$ 's expectations about other members' gamble choices and realized outcomes, as well as over the likelihood that they defect.

Given a realized income $y_{i}$, if $i$ stays she expects a current utility of

$$
v_{i}\left(S, y_{i}\right)=\sum_{e \in \mathcal{E}} \pi_{i}\left(e \mid y_{i}, S\right) u_{i}(e)
$$

while if $i$ defects she would get utility

$$
v_{i}^{D}\left(S, y_{i}\right)=u_{i}\left(y_{i}\right)-g_{i, S}
$$

\footnotetext{
${ }^{10}$ Note that since the rest of the community, i.e., those not in the defectors group, do not know of the defection, punishment itself may be more difficult to enforce as it is costly.
} 
Assuming that indifferent subjects do not defect, individual $i$ stays in the group if

$$
g_{i, S} \geq \widetilde{g}_{i, S}\left(y_{i}\right) \equiv \sum_{e \in \mathcal{E}} \pi_{i}\left(e \mid y_{i}, S\right)\left(u_{i}\left(y_{i}\right)-u_{i}(e)\right)
$$

and defects otherwise. For any subject $i$ in group $S$, let $d_{i}\left(y_{i}\right)=1$ if $i$ stays - the above inequality holds - and 0 if she defects.

Assume that uncertainty concerning others' behavior relates to their intrinsic motivations $g$. Let $\Gamma_{i j}(g)$ be the distribution of $i$ 's beliefs on $g_{j, S}$. If all types of $g_{j, S}$ participate, then

$$
\gamma_{i j}\left(y_{j}\right) \equiv 1-\Gamma_{i j}\left(\widetilde{g}_{j, S}\left(y_{j}\right)\right)
$$

is the probability that $j$ stays if his income is $y_{j}$ as assessed by $i$. These probabilities enter into $i$ 's expectations $\pi_{i}$.

Hence, if individual $i$ in group $S$ chooses gamble $\ell$, she expects utility

$$
U_{i}(S, \ell)=\sum_{y_{i} \in\left\{\underline{y}_{\ell}, \bar{y}_{\ell s}\right\}} \frac{1}{2}\left[d_{i}\left(y_{i}\right) v_{i}\left(S, y_{i}\right)+\left(1-d_{i}\left(y_{i}\right)\right) v_{i}^{D}\left(S, y_{i}\right)\right] \text {. }
$$

and individual $i$ 's choice of gamble $\ell_{i}$ will maximize $U_{i}\left(S, \ell_{i}\right)$ evaluated at the equilibrium gamble choice for other members of each type.

So, in contrast to $T 1$, under this treatment individuals' expectations regarding others' intrinsic motivations will affect their group formation decisions. Unless intrinsic motivations are and are believed to be sufficiently high, individuals will be less likely to join risk sharing groups. In addition, if others opt out with some positive probability, the insurance value of a group is reduced. Hence, subjects may not choose more risky gambles. Notice that, in general, an individual who plans to opt out of her group will choose a riskier lottery than an individual who plans to stay upon winning. This is because having to share one's winnings with some probability reduces the marginal utility from a high winning.

Treatment 3. Under $T 3$, subjects can opt out of their sharing groups after learning the outcome of their gamble, but only if they are prepared to confirm their defections in front of all the villagers present in their experimental session. Exogenous extrinsic commitment is limited in this treatment. However, there is no asymmetry in information regarding defections. So endogenous extrinsic commitment based on punishment in the form of social sanctions is more likely than under $T 2$.

For each $i \in S$ and $e \in \mathcal{E}$, we denote as $\rho_{i}(e \mid y, S)$ individual $i$ 's assessment of the probability of earning $e$, given her own gamble gain realization $y$, if she stays in the group $S$. As earlier, these probabilities reflect individual $i$ 's beliefs regarding others' gamble choices and realized outcomes, as well as the probability that they 
defect. Moreover, we let $\alpha_{i, S^{\prime}}$ be the probability that $i$ gives to the likelihood that a subset $S^{\prime}$ of $S \backslash i$ stays. ${ }^{11}$

Given her realized income $y_{i}$, individual $i$ expects the following utility if she stays in $S$,

$$
v_{i}\left(S, y_{i}\right)=\sum_{e \in \mathcal{E}} \rho_{i}\left(e \mid y_{i}, S\right) u_{i}(e)-\sum^{S^{\prime} \mid i \notin S^{\prime}}\left(1-\alpha_{i, S^{\prime}}\right) c_{i, S^{\prime}} .
$$

If $i$ defects then she would get utility

$$
v_{i}^{D}\left(S, y_{i}\right)=u_{i}\left(y_{i}\right)-g_{i, S}-f_{i, S}-\sum^{S^{\prime} \mid i \notin S^{\prime}}\left(1-\alpha_{i, S^{\prime}}\right) c_{i, S^{\prime}} .
$$

Notice that this formulation assumes that sanctions are carried out by everyone, including other defectors. This is the case in an equilibrium in which individuals who fail to carry out a punishment would themselves be sanctioned by the other group members and possibly by others in the community (recall that information on defections is public information).

Hence, $i$ stays in group $S$ if

$$
g_{i, S} \geq \widehat{g}_{i, S}\left(y_{i}\right) \equiv \sum_{e \in \mathcal{E}} \rho_{i}\left(e \mid y_{i}, S\right)\left(u_{i}\left(y_{i}\right)-u_{i}(e)\right)-f_{i, S}
$$

and defects otherwise. Let $d_{i}\left(y_{i}\right)=1$ if $i$ stays - the above inequality holds - and 0 if she opts out.

Given $\Gamma_{i j}(g)$, the distribution of $i$ 's beliefs over $g_{j, S}$, if all types of $g_{j}$ participate then

$$
\alpha_{i j}\left(y_{j}\right) \equiv 1-\Gamma_{i j}\left(\widehat{g}_{j, S}\left(y_{j}\right)\right)
$$

is the probability that $j$ stays if her income is $y_{j}$ as assessed by $i$. These probabilities enter into $\rho_{i}$.

Individual $i \in S$ with gamble $\ell$ has expected utility

$$
U_{i}\left(S, \ell_{i}\right)=\sum_{y_{i} \in\left\{\underline{y}_{\ell}, \bar{y}_{\ell}\right\}} \frac{1}{2}\left[d_{i}\left(y_{i}\right) v_{i}\left(S, y_{i}\right)+\left(1-d_{i}\left(y_{i}\right)\right) v_{i}^{D}\left(S, y_{i}\right)\right] .
$$

If she participates, individual $i$ chooses $\ell_{i}$ to maximize $U_{i}\left(S, \ell_{i}\right)$ given the equilibrium choice of other members of all possible type.

Under T3, the group selection process is affected not only by individuals' expectations regarding others' intrinsic motivations but also by their capacity to sanction others. With sanctions being easier to implement, since defections are common

\footnotetext{
${ }^{11}$ This accounts for the probability of any particular gamble realization and the probability of defection following each realization.
} 
knowledge, group members should be less likely to opt out under $T 3$ than $T 2$. And if social sanctions are sufficiently strong to deter all defections, their cost will be irrelevant and the outcomes should be similar to $T 1$.

\section{Results}

We now turn to the results of the experiment.

Defections. Do subjects opt out when exogenous extrinsic commitment is limited? Before turning to the analysis of risk sharing, it is useful to look at defections in the two treatments under which they were possible. Caution is required here as subjects could only defect if they were socially selected into a sharing group and subjects are less likely to be selected if they are expected to defect. Simple descriptive statistics will reflect this selection process as well as the subjects' subsequent defection decisions.

Figure 2 describes the decisions made by those subjects that joined groups under $T 2$ and T3. Under T2, 64 of 157 subjects joined sharing groups. Of these, 32 won high payoffs on the gambles of their choosing and of these 7 ( 22 percent) opted out of their sharing groups in secret. All of the subjects who won low payoffs stayed in their groups. Under T3, 66 of 183 subjects joined sharing groups. Of these 34 won high payoffs on the gambles of their choosing and of these only one (3 percent) opted out of her sharing group in public. Again, all of the subjects who won low payoffs stayed in their groups. The observation that only subjects who won their gambles decided to opt out suggests that they understood the game and the consequences of their actions.

The proportion of defections among high payoff winning group members differs significantly (five percent level) between the treatments, being lower when the defections had to be confirmed publicly. This suggests that either subjects who are more likely to defect are less likely to be selected into groups under $T 3$ or group members are deterred by social sanctioning when information on defections is public or both.

Group formation. Figure 3 graphs the size of groups that each of the subjects in $T 1, T 2$ and $T 3$ joined prior to Round 2 of the game. To aid comparisons between the treatments, relative frequencies are shown. A group size of one indicates that the subject played Round 2 as a singleton, i.e., did not join a sharing group. Thus, the bars on the far left of the figure indicate the proportions of subjects who did not join groups under each of the treatments and correspond to the summary statistics in Table 3. Only 31 percent of subjects did not join sharing groups under $T 1$ as compared to 59 and 64 percent under $T 2$ and $T 3$ respectively. A chi-squared test 
indicates that the likelihood of joining a group varies significantly (1 percent level) across treatments. Turning to group size, it is in $T 1$ that we see the largest group, a group of twelve. Groups of ten are a focal point due to the examples given during the instruction of the subjects. We see groups of ten under both $T 1$ and $T 2$. It is under $T 3$ that group size is most restricted. No groups of more than eight were formed under this treatment. These distributional differences are reflected in the means reported in Table 3. Conditional upon joining a group, subjects under $T 1$ and $T 2$ formed groups with 6.89 and 6.50 members on average, whereas subjects under T3 formed groups with only 3.97 members on average. Group size under T3 is significantly (1 percent level) smaller than group size under $T 1$ and $T 2$ according to t-tests.

Table 1 indicates that, despite the random assignment of villages to treatments, there are some significant differences in subject characteristics across treatments. Heads of households rather than their spouses were more likely to be subjects under $T 2$ and the subject pool was slightly older as a result. Further, there was a greater proportion of resettled villagers under $T 1$ and $T 3$ and a greater proportion of residents of Area 1 under the control, $C$, and T3. It is therefore important to examine the robustness of these findings to controlling for these subject characteristics. To this end, we conducted a series of regression analyses.

Table 4 presents the results of a probit analysis of whether subjects joined a group and then a linear regression analysis of group size conditional on group membership. In each case the standard errors are clustered at the village level. ${ }^{12}$ In the first two columns of the table, a dichotomous variable that takes the value one if a subject joined a sharing group and zero otherwise is regressed on the following: two treatment dummies ( $T 1$ is the basis for comparison); five dummies relating to the choice of gamble that the subject made in Round 1 (Gamble A is the basis for comparison), included to control for the subjects' attitudes towards risk; the subjects' winnings from Round 1, included to control for wealth effects; a dummy distinguishing resettled villagers from non-resettled villagers; two dummies relating to the geographical area within which the subjects' villages fell (Area 1 is the base for comparison); the number of households in the village, which corresponds to the number of subjects attending the session; and the subjects' sex, age, years of education, marital status, and whether they head a household.

The Probit analyses confirm that under both $T 2$ and $T 3$ subjects are significantly less likely to join a group than under $T 1$. We see also that females, more educated subjects and subjects in Area 2, which has the poorest soil and least reliable rainfall, are more likely to join groups. Only the two treatment dummies survive a general

\footnotetext{
${ }^{12}$ To control for the potential interdependence of errors as group formation is a social process within the villages.
} 
to specific process of elimination taking the ten percent level of significance as a cut-off.

When the size of the group that a subject joins is regressed on the same set of explanatory variables only one of the treatment dummies, the one relating to $T 3$, is significant. The coefficient on this dummy variable is also significantly different from that on the treatment dummy relating to $T 2$. Here, several of the subjects characteristics are significant and survive the general to specific process of elimination. Subjects in resettled villages and villages in Area 2 form significantly larger groups, as do women and married subjects.

Choice of gamble. The subjects choice of gamble in Rounds 1 and 2 under each of the treatments are presented in Table 3. According to chi-squared tests the distribution of choices across gambles does not vary between treatments in Round 1, but varies significantly (one percent level) between treatments in Round 2. To see where these variations lie, turn to Figure 4 which depicts the cumulative frequencies for the subjects' choices of gamble under the different treatments in Round 2. The most striking feature of these plots is the greater tendency for subjects under $T 1$ to choose the riskier gambles. Over one quarter of the subjects under $T 1$ chose gambles $E$ or $F$ as compared to between 10 and 13 percent of subjects under the other treatments. Further, only seven percent of subjects under $T 1$ chose gambles $A$ or $B$ as compared to between 14 and 17 percent of subjects under the other treatments.

A more careful analysis of gamble choice under each of the treatments must take account of each subject's decision in Round 1, thereby allowing us to focus on the extra risk that the subjects take on when pooling is an option. Figure 5 contains four transition matrices, one for each of the treatments. The numbers within the matrices are percentages. The $i j^{t h}$ element of a matrix is the percentage of the subjects who chose gamble $i$ in Round 1 who went on to choose gamble $j$ in Round 2. The frequencies associated with the Round 1 choices are shown in the columns to the right of the matrices. To facilitate easy reading of the matrices, the cells have been shaded in accordance with the percentage they contain; darker cells contain higher percentages. When the high percentages are concentrated down the principle diagonal it indicates that subjects tended to choose the same gamble in both rounds. When the high percentages are concentrated in the middle two columns it indicates that the subjects tended towards the middle-of-the-range gambles in Round 2 regardless of their choices in Round 1. If there are medium to high percentages in the bottom left-hand corner of a matrix it indicates that subjects tended to choose safer gambles in Round 2. And if there are medium to high percentages in the top right-hand corner of a matrix it indicates that subjects tended to choose riskier gambles in Round 2. The matrices for $C, T 2$ and 
T3 display quite dominant principle diagonals combined, to varying degrees, with dominant middle columns. The option to share risk under $T 2$ and $T 3$ appears not to be causing subjects to choose riskier gambles. In contrast, the matrix for $T 1$ is shaded in the top right-hand corner indicating that a considerable proportion of subjects chose riskier gambles in Round 2. In Figure 6 the matrix for $T 1$ is further sub-divided into those who did not and did join groups (left and righthand matrices respectively). It is in the latter that we see the concentration in the top right-hand corner.

Once again, we can use regression analysis to test the significance of these regularities in the data, while controlling for other factors that might have influenced the subjects' decisions. Here, we run ordered probit regressions to explain the choice of gamble and present the results in Table 5. A positive coefficient indicates that an increase in that variable is associated with an increase in the riskiness of the chosen gamble. In the first column the subjects' choices in Round 2 are regressed on a set of five dummy variables indicating their choices of gamble in Round 1 (Gamble $A$ is the base for comparison), their winnings from Round 1 to control for wealth effect, a set of three dummy variables indicating which treatment the decision was made under ( $C$ is the base for comparison), and the nine individual and village characteristics used previously in the analysis of group formation. All standard errors are clustered at the village level.

The dummies relating to choice of gamble in Round 1 are jointly, highly significant (one percent level) and those who won more in Round 1 assume greater risk in Round 2. The dummy identifying those who played under $T 1$ bears a positive and significant (five percent level) coefficient, indicating that they assumed more risk than those in the control. In contrast, the dummy identifying those who played under $T 2$ bears a negative and significant (ten percent level) coefficient, indicating that on average they assumed less risk than those in the control.

To investigate whether the effects of the treatments work through group formation, as Figure 6 suggested, in the second column we replace the three treatment dummy variables with a set of six, three identifying those who chose to join a group under each of the treatments and three identifying those who chose to play as singletons under each treatment ( $C$ remains the base for comparison). The three dummies relating to being in a group under $T 1, T 2$ or $T 3$ are jointly significant (five percent level), while those relating to playing as singletons under each treatment are not. A careful general to specific process yields the regression presented in the third column of Table 5. In this regression, of the treatment-group dummies, only the one identifying those who belonged to a group under $T 1$ is significant. The choices made under $T 2$ or $T 3$ or by singletons under $T 1$ were indistinguishable from those made under $C$. 


\section{Discussion of the Results}

In this section, we discuss the implications of the above experimental results for our understanding of the context in which risk sharing agreements among villagers take place. In particular, we focus on the importance of commitment and information on defections and on the role of extrinsic incentives and intrinsic motivations.

That subjects are more likely to join risk sharing groups and to join larger groups under $T 1$ than under $T 2$ and $T 3$ suggests that exogenous extrinsic commitment is valuable and that intrinsic motivations are not sufficient to guarantee the commitment of all subjects. In other words, the loss of utility that individuals would suffer due to feelings of guilt or denial of their underlying altruism were they to defect on others are not always large enough to prevent defections. Moreover, the lower level of risk sharing under $T 3$ compared to $T 1$ indicates that endogenous extrinsic commitment based on the possibility of punishment between the subjects must be either limited or costly or both.

What is a priori more surprising is that subjects form larger risk sharing groups under $T 2$ than $T 3$. That the outcomes differ under the two treatments suggests that subjects do not fully share information on defections under $T 2$ and that the greater possibility of punishment under $T 3$ is important. However, given that punishment is easier under $T 3$ than $T 2$, we might expect that subjects would be more likely to form groups and would form larger groups under $T 3$ than $T 2$, whereas what we observe is the opposite. We suggest two possible explanations, one relating to the cost of punishment and one to time-inconsistent preferences.

Costly Punishment. A first possible explanation derives from recognizing that punishment is not only costly to receive but may also be costly to inflict. If the cost of punishing others is not insignificant (as would clearly be the case when the punishment takes the form of exclusion from economic and social exchange) and if the threat of punishment is not sufficient to ensure that punishment need only be carried out rarely, subjects may prefer to enter into fewer agreements in the first place. $^{13}$

To see this, consider the model outlined in Section 3. Given that harsher punishment is possible in $T 3$ than $T 2$, we would expect that, if the same groups were formed under each treatment, there would be fewer defections under $T 3$ than $T 2$. The descriptive statistics on defections reported in Figure 2 are consistent with this. However, this does not imply that forming a large risk sharing group is more

\footnotetext{
${ }^{13}$ Note that the cost of punishment to the punisher could be associated with its execution, the risk of making an incorrect judgment and incurring social punishments oneself as a result, or with some form of conflict aversion as discussed in Harowitz (2001)
} 
desirable under $T 3$ than $T 2$. In order for a group $S$ to form, it must contain no preferred subgroups, including singletons.

The cost of punishing defectors under $T 3$ does not affect the temptation to defect in (3), but pushes the expected utility of being in a given group under $T 3$ down. This reduces the benefits associated with joining a group or adding a member to a group. In addition, if this discouragement is stronger for individuals with high levels of intrinsic motivation $g$, this will be reflected in others' expectations about the likelihood of defections and thereby further reduce their willingness to join a group.

This might explain why sharing groups are smaller under $T 3$ than under $T 2$. This would be more likely to happen when intrinsic motivations $(g)$ are sufficient to stop people defecting at least some of the time under $T 2$ and social sanctions $(f)$ are costly to inflict and not sufficient to discourage all defections. The following example illustrates this idea.

Consider two individuals who are identical except, potentially, with respect to their intrinsic motivations and who form a sharing group. Assume that there is only one gamble that pays either $y$ or $\bar{y}$ with probability $1 / 2$, and denote as $y_{m}$ the average payoff $\frac{y+\bar{y}}{2}$. These individuals would consider defecting only after winning their gamble, i.e. receiving $\bar{y}$. Hence, $\gamma_{i j}(y)=\alpha_{i j}(y)=1$ and, using symmetry, let $\gamma=\gamma_{i j}(\bar{y})$ and $\alpha=\alpha_{i j}(\bar{y})$ denote the probability that the other stays in the group after winning his gamble under $T 2$ and $T 3$ respectively.

In this example, we can rewrite (2), the incentive constraint under $T 2$ as

$$
g_{i} \geq \widetilde{g} \equiv \frac{1}{2}\left(u_{i}(\bar{y})-u_{i}\left(y_{m}\right)\right) .
$$

Now assume that intrinsic motivations are private information and are distributed according to a distribution $\Gamma(g)$. $\Gamma$ is common knowledge and characterizes individuals' beliefs about the intrinsic motivations of the other. If all types of $g$ participate, then the probability, as assessed by $i$, that $j$ will stay in the group after winning is given by $\gamma=1-\Gamma(\widetilde{g})$. Let $d_{i}$ be one if $i$ stays in the group after winning and 0 otherwise. Individual $i$ 's expected utility of being in a group with $j$ is then

$$
U^{T 2}(i j)=\frac{1}{4}(2-\gamma) u(\underline{y})+\frac{1}{4}\left(\gamma+d_{i}\right) u\left(y_{m}\right)+\frac{1}{2}\left(1-\frac{1}{2} d_{i}\right) u(\bar{y})-\frac{1}{2}\left(1-d_{i}\right) g_{i} .
$$

Similarly, (3), the incentive constraint under $T 3$, becomes

$$
g_{i} \geq \widehat{g} \equiv \frac{1}{2}\left(u_{i}(\bar{y})-u_{i}\left(y_{m}\right)\right)-f .
$$


Hence, if all types of $g_{j}$ participate then $\alpha \equiv 1-\Gamma(\widehat{g})$ is $i$ 's belief about the probability that $j$ will stay in the group after winning.

A quick comparison of (5) and (6) tells us that $\widetilde{g}>\widehat{g}$ so the probability of defection is larger under $T 2$ than $T 3, \gamma<\alpha$, as expected. However, due to the cost of punishment the expected utility of being in a sharing group can be lower under T3. Indeed, $i$ 's expected utility of being in a group with $j$ under $T 3$ is

$U^{T 3}(i j)=\frac{1}{4}(2-\alpha) u(\underline{y})+\frac{1}{4}\left(\alpha+\widetilde{1}_{i}\right) u\left(y_{m}\right)+\frac{1}{2}\left(1-\frac{1}{2} \widetilde{1}_{i}\right) u(\bar{y})-\frac{1}{2}\left(1-\widetilde{1}_{i}\right)\left(g_{i}+f\right)-\frac{1}{2}(1-\alpha) c$,

where $\widetilde{1}_{i}$ is one if $i$ stays when winning and 0 otherwise.

If this expected utility is less than the utility of being a singleton, our two individuals will prefer not to form a group under $T 3$ while they may be happy to do so under $T 2$. Let's take a numerical example.

EXAMPLE 1 Consider a log utility function of consumption $\ln (c+k)$ where $k=100$ and a gamble that pays $\underline{y}=60$ or $\bar{y}=300$ with probability $1 / 2$. For a singleton

$$
U_{i}=\frac{1}{2}(\ln (k+\underline{y})+\ln (k+\bar{y}))=5.576 .
$$

Assume that punishment costs the same amount to both the recipient and inflictor $f=c=0.05$. In this case, the threshold intrinsic motivations are $\widetilde{g}=0.173$ and $\widehat{g}=0.123$.

Take $\Gamma$ to be a log normal distribution with parameter $\mu=0$ and $\sigma=10$. Calculating the expected utilities we find that

$$
U^{T 2}(i j)=5.565>U_{i}=5.576>U^{T 3}(i j)=5.557 .
$$

Hence, individuals form groups under $T 2$ but not $T 3$.

The same reasoning can be used to explain why a group of a given size may welcome a new member under $T 2$ but not under $T 3$.

Time-inconsistent Preferences. Alternatively or in addition, issues of selfcontrol could help us interpret our findings. Individuals could have time-inconsistent preferences in the form of hyperbolic discounting (see Laibson (1997) and O'Donoghue and Rabin (1999) among others). Under T3, potential defectors know that they will face the social sanctions later than they will experience the gain from the gamble and their immediate feelings of guilt, should they choose to defect. Hence, it is entirely possible that, on learning that she won her gamble, she would discount future sanctions more heavily compared to her winnings, than she would ex-ante, i.e., at the time of forming a group. In this case, the punishment $f$ that enters her incentive constraint (3) is lower than the value of the punishment $\widetilde{f}$ that enters her expected utility. 
Now consider the previous example with two individuals and one gamble choice. The incentive constraint in (6) determines the likelihood that the other defects if all types participate as $\alpha \equiv 1-\Gamma(\widehat{g})$. However, the same individual may view the situation differently ex-ante. If social sanctions represent a punishment of $\widetilde{f}>f$ ex-ante then the threshold

$$
\underline{g} \equiv \frac{1}{2}\left(u_{i}(\bar{y})-u_{i}\left(y_{m}\right)\right)-\widetilde{f} .
$$

is the value of intrinsic motivations above which an individual would ex-ante rather not defect.

Since $g<\widetilde{g}$, individuals with intrinsic motivation $g_{i}$ between $g$ and $\widetilde{g}$ prefer not to defect but would defect all the same. If the difference is large, then these individuals may prefer not to join a group rather than join and then defect. In this case, choosing not to form risk sharing groups could, using Elster's (1984) terminology, be a form of pre-commitment. These participation decisions will be reflected in $\alpha$ which will increase accordingly. Note that this affects subjects who would defect if they joined a group and so further reduces the observed defection rate under T3. So once again, participation in sharing groups can be lower when social sanctions are possible.

In future work it would be interesting to distinguish between these two explanations - costly punishment and time-inconsistency. Depending on when winning becomes salient (and the relative discounting between the gamble gain and the future sanctions changes), one could compare the behavior of individuals asked whether they want to opt out just after learning that they had won their gamble (as is the case in this experiment) with that of individuals asked some time earlier whether they will opt out contingent on winning or loosing their gamble. A difference in behavior would be a sign of time-inconsistency. New experimental designs could also help us directly identify the effects of the costs of punishment to both the punisher and the recipient. However, for these experiments to be truly informative they would need to be preceded by a careful investigation into the forms that such punishments take in everyday life.

\section{COMPARISON WITH REAL RISK SHARING NETWORKS}

An interesting question is whether subjects who join the same group in our experiment share risk with each other in real life. A comparison of the groups formed within our experiment with real life risk sharing networks would shed some light on the external validity of our experiment. ${ }^{14}$

\footnotetext{
${ }^{14}$ For other examples of similar investigations into the external validity of behavioral experiments conducted in the field, see Karlan (2005) and Schechter (2007).
} 
We are able to do precisely this for part of our sample. At the same time that we were in the field, Dekker (2002) was conducting an in-depth study of flows of assistance between households in five of the 23 villages involved in our experiment. Those villages were Moturamhepo, Zvataida, and Mudzinge, Muringamombe, and Pedzanhamo. Dekker asked every household head or senior woman in these villages to name the households in their village to whom they had given assistance and from whom they had received assistance during the preceding twelve months. We use these survey data to investigate whether the groups formed during the experiment bear any resemblance to the real risk sharing networks within these five villages.

From the survey data, we construct two relational matrices for each village characterizing the risk sharing network among the subjects of our experiment (a subset of the villagers). In the 'assistance given' matrix for a particular village, the $i j^{t h}$ takes the value one if household $i$ reported giving assistance to household $j \neq i$ or vice versa, one if $i=j$ and zero otherwise. Similarly, the $i j^{\text {th }}$ element in the 'assistance received' matrix for a particular village takes the value one if household $i$ reported receiving assistance from household $j \neq i$ or vice versa, one for the diagonal elements and zero otherwise. With no measurement error these matrices should be the transpose of each other. However, this is not the case and, consistent with there being a stigma associated with needing or receiving assistance and/or high status associate with giving assistance, the 'assistance given' matrices indicate more relations than the 'assistance received' matrices, i.e., there are many more ones in the former than in the latter. For this reason, and because there is no way of telling which of the two matrices is a better reflection of the actual pattern of transfers, we repeat the analysis described below twice for each village, once using the 'assistance received' matrix, and once using the 'assistance given' matrix.

Next, for each of the five villages, we construct another matrix representing the group formation within the experiment. In these matrices the $i j^{\text {th }}$ element takes the value one if the representative from household $i$ in the experiment was in the same group as the representative from household $j$, and zero otherwise.

We are interested in whether the experimental group formation matrices are related to the 'assistance given' and 'assistance received' matrices. In other words, we want to know whether the likelihood of two experimental subjects from the same village joining the same risk sharing group is related to whether they have given or received assistance from one another in the past.

Tests for this relationship cannot be based on standard correlations between the elements of each experimental group formation matrix and its corresponding 'assistance given' and 'assistance received' matrices. This is because we cannot assume that the elements within the matrices are independent of one another as each matrix represents a fully enumerated and interrelated social system. Instead, we use 
the Quadratic Assignment Procedure - a non-parametric procedure commonly used in social network analysis (see Krackhardt (1987)) - to measure the network correlation between our matrices. We repeat the following procedure for each village.

First, we compute a match score $m$ for the experimental group formation matrix and one of the survey network matrices, either the 'assistance given' or 'assistance received' matrix, by counting the number of times that the corresponding cells in the two matrices are the same, i.e., both equal one or both equal zero. ${ }^{15}$ This provides us with a matrix-pair-specific match score. Second, we simulate 10,000 permutations of one of the two matrices, say the experimental group formation matrix, by randomly but synchronously permutating its rows and columns. In each permutation, the order of the rows of the original matrix is randomly reshuffled and then the columns are placed in that same order. ${ }^{16}$ In essence, such permutations preserve the network structure but randomize the subjects' locations in the network. For each of the simulated matrices indexed by $\pi=1, \ldots T$ where $T=10,000$, we compute the match score $m_{\pi}$ exactly as we did for the original matrix. Third, we calculate $P$ as twice the proportion of simulated matrices with a higher match score, that is so that $m_{\pi}>m .{ }^{17}$ If less than ten percent of the randomized matches have a higher match score than the actual matrix, $P<0.1$, we conclude that the matrices are related with a 'significance level' equal to $P$.

The significance levels $P$, for the five villages for which we have data and for both the 'assistance given' and the 'assistance received' matrices, are reported in Table 6. ${ }^{18}$ We see that in three out of the five villages, Moturamhepo, Zvataida, and Mudzinge, the match between group formation in the game and patterns of assistance reported as given is significant. For one of the other villages, Muringamombe, the match between group formation in the game and patterns of assistance reported as received is significant. For the fifth village, Pedzanhamo, neither match is significant.

These results are particularly encouraging given the fact that these tests are subject to two sources of bias both of which may suppress the significance level defined

\footnotetext{
${ }^{15}$ Diagonal entries are ignored.

${ }^{16}$ After the permutation, the following is true. For each row, the first subscript is shared by all the entries in the row. For each column, the second subscript is shared. And each diagonal element moves to a new position but remains a diagonal element.

${ }^{17}$ If the experimental group formation matrix and the survey network matrices were uncorrelated, we would expect around $50 \%$ of the simulated matrices to have a higher match score. Hence, by looking at twice the proportion of simulated matrices with a higher match score, we would expect $P$ to be around $100 \%$ for uncorrelated matrices.

${ }^{18}$ These tests were performed using UCINET, a social network analysis software. We only present significance levels as the match statistics themselves are not comparable across villages and have no meaning beyond the context of the tests. The match statistics are available from the authors upon request.
} 
above. First, in the survey data an actual flow of assistance is observed only if one household is in need and another is both willing and able to respond, whereas in the experiment only the condition of willingness must be met in order for two subjects to become linked by group membership. Hence, the survey data captures ex post flows of assistance while the experimental data captures ex ante agreements relating to flows of assistance if unequal payoffs arise. Thus, the experimental group matrices are likely to contain many more relations than either of the 'assistance' matrices and the match statistic is likely to be suppressed as a result. This bias is likely to be greater when the less dense assistance received matrices are being used. So, we expect more significant results in the tests involving the 'assistance given' matrices. The second potential source of bias arises if the subjects in the experiment and those making real risk sharing decisions are distinct. The majority of the experimental subjects were household heads or senior women who would have been involved in real risk sharing decisions. However, in Pedzanhamo a large proportion of the experimental subjects were young dependents rather than senior household members. Here, once again we expect to see suppressed levels of significance.

\section{Conclusion}

In this paper, we use a framed field experiment to test the implications of limited commitment and punishment possibilities in a risk sharing game. We find that subjects engage in more risk sharing and risk taking when provided with a full commitment technology as in Treatment $1(T 1)$. This suggests that a lack of commitment limits the risk sharing agreements that these villagers can form in real life. We also find that, when commitment is limited, more risk sharing takes place under asymmetric information on defections as in Treatment 2 (T2) than when defections are public as in Treatment 3 (T3). That substantial risk sharing takes place under Treatment $2(T 2)$ suggests that intrinsic motivations such as altruism, guilt, etc. do play an important role in risk sharing agreements. Further, that risk sharing is limited under Treatment $3(T 3)$ suggests that social sanctions are limited as a basis for commitment. However, that less risk sharing occurs under Treatment 3 (T3) than Treatment $2(T 2)$ is surprising since it is easier to punish defectors when there is symmetric information on defections. We provide two possible explanations for this result. First, individuals may suffer from timeinconsistent preferences. Upon receiving a high gamble payoff they may be tempted and discount future sanctions too heavily (from their ex-ante perspective). In this case not participating in a sharing group is a way to avoid the temptation to

defect. Second, social sanctions are not only costly to receive but also often costly to administer. Hence, although social sanctions reduce the likelihood of defection, 
it is entirely possible that individuals would prefer not to form sharing groups or to form smaller ones under Treatment 3 (T3) than Treatment 2 (T2). 


\section{References}

(1) Alderman and Paxson (1992), "Do the Poor Insure? A Synthesis of the Literature on Risk and Consumption in Developing Countries," World Bank Policy Research Working Paper.

(2) Binswanger, H. P. (1980), "Attitudes toward Risk: Experimental measurement in rural India," American Journal of Agricultural Economics 62(3), 395-407.

(3) Bohnet, I., B. Frey, and S. Huck (2001), "More Order with Less Law: On Contract Enforcement, Trust, and Crowding," American Political Science Review 95(1), 131-143.

(4) Bowles, S. J. Carpenter, and H. Gintis (2001), "Mutual Monitoring in Teams: The Effects of Residual Claimancy and Reciprocity," Santa Fe Institute Working Paper 98-08-074E.

(5) Cardenas, J. C., J. Stranlund, and C. Willis (2000), "Local Environmental Control and Institutional Crowding-out," World-Development 28(10), 1719-33.

(6) Carpenter, J. and E. Seki (2005) "Do Social Preferences Increase Productivity? Field Experimental Evidence from Fishermen in Toyama Bay," IZA Discussion Paper No. 1697.

(7) Charness, G, and G. Genicot (2006) "An Experimental Test of Risk-Sharing Arrangements," Working Paper.

(8) Coate, S. and M. Ravallion (1993), "Reciprocity without Commitment: Characterisations and Performance of Informal Risk-Sharing Arrangements," Journal of Development Economics 40, 1-24.

(9) Dekker, M. (2002), "Risk Sharing Relations in a Village," mimeo, Department of General and Development Economics, Free University, Amsterdam.

(10) De Weerdt, J (2002), "Social Networks, Transfers and Insurance in Developing Countries," Ph.D., KULeuven.

(11) Elster, J (1984), "Ulysses and the Sirens: Studies in Rationality and Irrationality," Cambridge University Press, Cambridge.

(12) Fafchamps, M. (1998), "Risk Sharing and Quasi-credit," Journal of International Trade and Development 8, 257-278.

(13) Fafchamps, M. and Lund, S. (2003), "Risk-sharing Networks in Rural Philippines,' Journal of Development Economics 71(2), 261-287.

(14) Falk, A., E. Fehr, and U. Fischbacher (2000), "Informal Sanctions," Institute for Empirical Research in Economics, University of Zurich, Working Paper Series, ISSN 1424-0459.

(15) Foster, A. and M. R. Rosenzweig, (2001), "Imperfect Commitment, Altruism, and the Family: Evidence from Transfer Behavior in Low-Income Rural Areas," The Review of Economics and Statistics, 83(3), 389-407. 
(16) Genicot, G. and D. Ray (2003), "Group Formation in Risk Sharing Arrangements," Review of Economic Studies 70, 87-113.

(17) Grimard, F. (1997), "Household Consumption Smoothing through Ethnic Ties: Evidence for Côte d'Ivoire," Journal of Development Economics 53, 391-421.

(18) Harowitz, S. (2001), "The Balance of Power: Formal Perfection and Practical Flaws," Journal of Peace Research 38(6), 705-22.

(19) Harrison, G.W. and J.A. List (2004), "Field Experiments," Journal of Economic Literature XLII, 1009-1055.

(20) Holtzmann, R., T. Packard, and J. Cuesta (2000), "Extending Coverage in Multi-pillar Pension Systems: Constraints and Hypotheses, Preliminary Evidence and Future Research Agenda," Social Protection Working Paper, World Bank.

(21) Karlan, D. (2005), "Using Experimental Economics to Measure Social Capital and Predict Financial Decisions," American Economic Review 95(5), 1688-1699.

(22) Kocherlakota, N. (1996), "Implications of Efficient Risk Sharing without Commitment," Review of Economic Studies 63, 595-609.

(23) Krackhardt, D. (1987), "QAP Partialling as a Test of Spuriousness," Social Networks 1, 215-239.

(24) Laibson, D., (1997), "Golden Eggs and Hyperbolic Discounting," Quarterly Journal of Economics 112, 443-77.

(25) Ligon, E. (1998), "Risk-sharing and Information in Villages Economies," Review of Economic Studies 65, 847-864.

(26) Ligon, E., J. P. Thomas, and T. Worrall (2002), "Informal Insurance Arrangements with Limited Commitment: Theory and Evidence from Village Economies," Review of Economic Studies 69(1), 209-44.

(27) Masclet, D., C. Noussair, S. Tucker and M. Villeval (2003) "Monetary and Non-Monetary Punishment in the Voluntary Contributions Mechanism," American Economic Review 93(1), 366-380.

(28) Morduch, J. (1991), "Consumption Smoothing across Space: Tests for village-level responses to risk," Harvard University mimeo.

(29) O'Donoghue, T., and M. Rabin (1999a), "Doing it Now or Later," American Economic Review 89, 103-24.

(30) Platteau, J. P. (1994a), "Behind the Market Stage where Real Societies Exist Part I: The Role of Public and Private Order Institutions," Journal of Development Studies 30(3), 533577.

(31) Platteau, J. P. (1994b), "Behind the Market Stage where Real Societies Exist Part II: The Role of Moral Norms," Journal of Development Studies 30(3), 753817. 
(32) Posner, R. A. and E. B. Rasmusen (1999), "Creating and Enforcing Norms, with Special Reference to Sanctions," International Review of Law and Economics 19, 369-82.

(33) Rabin, Matthew (2000), "Risk Aversion and Expected Utility Theory: A Calibration Theorem,", Econometrica 68, 1281-92.

(34) Rosenzweig, M. R. and O. Stark (1989), "Consumption Smoothing, Migration, and Marriage: Evidence from Rural India," Journal of Political Economics 101, 223-244.

(35) Ravallion, M. and S. Chaudhuri (1991), "Testing Risk-sharing in Three Indian Villages,' World Bank mimeo.

(36) Ravallion, M. and L. Dearden (1988), "Social Security in a "Moral Economy': An Empirical Analysis for Java," Review of Economics and Statistics 70, 36-44.

(37) Rege M. and K. Telle (2004), "The Impact of Social Approval and Framing on Cooperation in Public Good Situations," Journal of Public Economics 88(7-8), 16251644

(38) Schechter, Laura (2007), "Theft, Gift-Giving, and Trustworthiness: Honesty is Its Own Reward in Rural Paraguay," American Economic Review, forthcoming.

(39) Sutter, M., S. Haigner and M.G. Kocher (2007), "Choosing the Carrot or the Stick? Endogenous Institutional Choice in Social Dilemma Situations" mimeo.

(40) Townsend, R. M. (1994), "Risk and Insurance in Village India," Econometrica 62, 539-591.

(41) Udry, C. (1994), "Risk and Insurance in a Rural Credit Market: An Empirical Investigation in Northern Nigeria," Review of Economic Studies $\mathbf{6 1}$, 495-526. 


\section{Table 1: Subject characteristics}

\begin{tabular}{|c|c|c|c|c|c|c|c|}
\hline & $\begin{array}{l}\text { Subjects in } \\
\text { Round } 1\end{array}$ & $\begin{array}{l}\text { Subjects in } \\
\text { Round } 2\end{array}$ & $\begin{array}{c}\text { Subjects in } \\
\text { Round } 2 \\
\text { C }\end{array}$ & $\begin{array}{c}\text { Subjects in } \\
\text { Round } 2 \\
\text { T1 }\end{array}$ & $\begin{array}{c}\text { Subjects in } \\
\text { Round } 2 \\
\text { T2 }\end{array}$ & $\begin{array}{c}\text { Subjects in } \\
\text { Round } 2 \\
\text { T3 }\end{array}$ & $\begin{array}{l}\text { Survey } \\
\text { data }\end{array}$ \\
\hline Number of subjects & 640 & 642 & 86 & 216 & 157 & 183 & $2108-2128$ \\
\hline Females & $47 \%$ & $48 \%$ & $55 \%$ & $50 \%$ & $41 \%$ & $48 \%$ & $54 \%$ \\
\hline Married & $69 \%$ & $69 \%$ & $62 \%$ & $68 \%$ & $73 \%$ & $70 \%$ & $57 \%$ \\
\hline Household head ${ }^{\#}$ & $42 \%$ & $40 \%$ & $28 \%$ & $37 \%$ & $56 \%$ & $37 \%$ & $19 \%$ \\
\hline Spouse of head"\# & $21 \%$ & $22 \%$ & $24 \%$ & $22 \%$ & $15 \%$ & $26 \%$ & $18 \%$ \\
\hline Age in years ${ }^{\# \#}$ & 42 & 42 & 39 & 40 & 44 & 42 & 35 \\
\hline Education in years & 7 & 7 & 7 & 7 & 7 & 7 & 7 \\
\hline Resettled $^{\#}$ & $83 \%$ & $83 \%$ & $79 \%$ & $89 \%$ & $71 \%$ & $88 \%$ & $79 \%$ \\
\hline \multicolumn{8}{|l|}{ Area of residency } \\
\hline Area 1 & $38 \%$ & $38 \%$ & $43 \%$ & $37 \%$ & $32 \%$ & $43 \%$ & $57 \%$ \\
\hline Area 2 & $34 \%$ & $34 \%$ & $36 \%$ & $26 \%$ & $43 \%$ & $37 \%$ & $22 \%$ \\
\hline Area 3 & $28 \%$ & $27 \%$ & $20 \%$ & $37 \%$ & $25 \%$ & $21 \%$ & $20 \%$ \\
\hline
\end{tabular}

Notes: $\mathrm{C}=$ control, subjects play solo; $\mathrm{T} 1$ = group formation with full commitment; $\mathrm{T} 2$ = group formation with private defection possible; T3 = group formation with public defection possible.

\# - variation across treatments significant at $1 \%$ level (Chi-squared test); \#\# - variation across treatments significant at $10 \%$ level (Chi-squared test); \#\#\# - variation across treatments significant at 10\% level (linear regression of age on 3 treatment dummies). \#\#\#\# Data from the Zimbabwe Rural Household Income Dynamics Survey, 2001; over 15 year olds only.

\section{Table 2: The gamble choice game: payoffs, expected values, variances, and corresponding levels of risk aversion}

\begin{tabular}{lccccc}
\hline $\begin{array}{c}\text { Gamble } \\
\text { Choice }\end{array}$ & $\begin{array}{c}\text { High payoff } \\
\text { on blue } \\
\text { background }\end{array}$ & $\begin{array}{c}\text { Low payoff } \\
\text { on yellow } \\
\text { background }\end{array}$ & $\begin{array}{c}\text { Expected } \\
\text { value }\end{array}$ & $\begin{array}{c}\text { Variance in } \\
\text { payoffs }\end{array}$ & $\begin{array}{c}\text { Risk aversion range } \\
\text { (CRRA) }\end{array}$ \\
\hline Gamble A & 100 & 100 & 100 & 0 & infinity to 7.51 \\
Gamble B & 190 & 90 & 140 & 50 & 7.51 to 1.74 \\
Gamble C & 240 & 80 & 160 & 80 & 1.74 to 0.81 \\
Gamble D & 300 & 60 & 180 & 120 & 0.81 to 0.32 \\
Gamble E & 380 & 20 & 200 & 180 & 0.32 to 0.00 \\
Gamble F & 400 & 0 & 200 & 200 & 0 to -ve infinity \\
\hline
\end{tabular}

Notes: Gamble $\mathbf{A}$ is the least risky but has the lowest expected value. Gamble $\mathbf{F}$ is the most risky but has the joint (with gamble E) highest expected value. 
Table 3: Summary of experimental data

\begin{tabular}{|c|c|c|c|c|c|}
\hline Treatment & $\mathbf{C}$ & T1 & $\mathbf{T} 2$ & T3 & All \\
\hline Number of subjects & 86 & 216 & 157 & 183 & 642 \\
\hline \multicolumn{6}{|l|}{ Group joining: proportion who } \\
\hline joined groups for Round $2^{\#}$ & - & $68.98 \%$ & $40.76 \%$ & $36.07 \%$ & $50.18 \%$ \\
\hline played solo in Round $2^{*}$ & - & $31.02 \%$ & $59.24 \%$ & $63.93 \%$ & $49.82 \%$ \\
\hline Mean size of group joined: & - & & & & \\
\hline unconditional $^{\# \#}$ & - & 5.06 & 3.24 & 2.07 & 3.56 \\
\hline conditional upon joining a group & - & 6.89 & 6.50 & 3.97 & 6.11 \\
\hline \multicolumn{6}{|l|}{ Gamble choices in Round 1: } \\
\hline Gamble A & $11 \%$ & $8 \%$ & $12 \%$ & $12 \%$ & $10 \%$ \\
\hline Gamble B & $17 \%$ & $11 \%$ & $13 \%$ & $15 \%$ & $13 \%$ \\
\hline Gamble C & $28 \%$ & $37 \%$ & $26 \%$ & $32 \%$ & $32 \%$ \\
\hline Gamble D & $33 \%$ & $35 \%$ & $37 \%$ & $32 \%$ & $35 \%$ \\
\hline Gamble E & $2 \%$ & $6 \%$ & $5 \%$ & $5 \%$ & $5 \%$ \\
\hline Gamble F & $8 \%$ & $4 \%$ & $6 \%$ & $3 \%$ & $5 \%$ \\
\hline \multicolumn{6}{|l|}{ Gamble choices in Round 2:" } \\
\hline Gamble A & $1 \%$ & $2 \%$ & $3 \%$ & $8 \%$ & $4 \%$ \\
\hline Gamble B & $13 \%$ & $5 \%$ & $11 \%$ & $10 \%$ & $9 \%$ \\
\hline Gamble C & $31 \%$ & $35 \%$ & $44 \%$ & $38 \%$ & $38 \%$ \\
\hline Gamble D & $42 \%$ & $31 \%$ & $32 \%$ & $32 \%$ & $33 \%$ \\
\hline Gamble E & $12 \%$ & $14 \%$ & $5 \%$ & $9 \%$ & $10 \%$ \\
\hline Gamble F & $1 \%$ & $13 \%$ & $4 \%$ & $3 \%$ & $6 \%$ \\
\hline Winnings in round 1 & $\$ 147$ & $\$ 165$ & $\$ 161$ & $\$ 152$ & $\$ 158$ \\
\hline Winnings in round 2 & $\$ 175$ & $\$ 177$ & $\$ 163$ & $\$ 173$ & $\$ 172$ \\
\hline
\end{tabular}

Notes: $\mathrm{C}=$ control; $\mathrm{T} 1$ = full commitment; $\mathrm{T} 2$ = private defection; $\mathrm{T} 3$ = public defection.

Gambles A to $\mathrm{F}$ are ordered by increasing risk and expected value.

\# - variation across treatments significant at 1\% level (Chi-squared test); \#\# - all pair wise differences in means significant at $1 \%$ level (t-tests with equal variance assumed); \#\#\# - significantly lower (at $1 \%$ level) mean under T4 than under T2 and T3 (t-tests with equal variance assumed). 
Table 4: Group membership and group size

\begin{tabular}{|c|c|c|c|c|c|c|c|c|}
\hline & \multicolumn{4}{|c|}{ Probit of group formation } & \multicolumn{4}{|c|}{ Group size conditional on formation } \\
\hline & Coef. & s.e. & Coef. & s.e. & Coef. & s.e. & Coef. & s.e. \\
\hline Constant & 0.058 & 0.820 & 0.495 & $0.173^{* * *}$ & 2.687 & $1.348 *$ & 3.348 & $0.830^{* * *}$ \\
\hline $\mathrm{T} 2$ & -0.729 & $0.404 *$ & -0.729 & $0.395 *$ & -0.431 & 0.685 & -0.359 & 0.782 \\
\hline T3 & -0.858 & $0.205^{* * *}$ & -0.852 & $0.217^{* * *}$ & -3.321 & $0.704 * * *$ & -3.122 & $0.660^{* * * *}$ \\
\hline \multicolumn{9}{|c|}{ Gamble choice in round $1^{*}$} \\
\hline Gamble B & 0.271 & 0.223 & & & 0.124 & 0.555 & & \\
\hline Gamble C & -0.084 & 0.236 & & & 0.017 & 0.642 & & \\
\hline Gamble D & 0.171 & 0.244 & & & 0.460 & 0.586 & & \\
\hline Gamble E & 0.326 & 0.414 & & & 1.103 & 0.950 & & \\
\hline Gamble F & 0.051 & 0.356 & & & 0.513 & 0.947 & & \\
\hline Winnings in round 1 & -0.001 & 0.001 & & & -0.001 & 0.001 & & \\
\hline Resettled & 0.009 & 0.352 & & & 1.143 & $0.510^{* *}$ & 0.978 & $0.531 *$ \\
\hline Area 2 & 0.523 & $0.265 * *$ & & & 1.868 & $0.656 * * *$ & 2.059 & $0.693 * * *$ \\
\hline Area 3 & 0.315 & 0.297 & & & 0.453 & 0.674 & 0.643 & 0.693 \\
\hline H'holds in village & -0.006 & 0.013 & & & 0.024 & 0.028 & & \\
\hline Female & 0.375 & $0.212 *$ & & & 1.782 & $0.595 * * *$ & 1.811 & $0.559^{* * *}$ \\
\hline Age in years & 0.003 & 0.005 & & & -0.004 & 0.010 & & \\
\hline Education in years & 0.032 & $0.019 *$ & & & -0.026 & 0.073 & & \\
\hline Married & -0.077 & 0.137 & & & 1.118 & $0.385 * * *$ & 1.150 & $0.341_{* * *}$ \\
\hline Household head & -0.036 & 0.192 & & & -0.086 & 0.411 & & \\
\hline $\begin{array}{l}\text { Joint significance of } \\
\text { round } 1 \text { choice }^{\# \#}\end{array}$ & \multicolumn{4}{|c|}{0.197} & \multicolumn{2}{|c|}{0.444} & & \\
\hline $\begin{array}{l}\text { Joint significance of } \\
\text { areas }^{\# \#}\end{array}$ & \multicolumn{2}{|c|}{0.141} & & & \multicolumn{2}{|c|}{0.034} & \multicolumn{2}{|c|}{0.026} \\
\hline $\mathrm{R}^{2}$ & \multirow{2}{*}{\multicolumn{2}{|c|}{0.108}} & \multicolumn{2}{|c|}{0.067} & \multicolumn{2}{|c|}{0.406} & \multicolumn{2}{|c|}{0.396} \\
\hline Obs. & & & \multicolumn{2}{|c|}{556} & \multicolumn{2}{|c|}{274} & \multicolumn{2}{|c|}{279} \\
\hline
\end{tabular}

Notes: The dependent variable in the Probit regressions is a dummy that takes on value one if a subject is in a group and zero otherwise. The regressions for group size conditional on joining a group are linear.

Only treatments where group formation is possible were considered.

$\mathrm{T} 1$ = full commitment; $\mathrm{T} 2$ = private defection; $\mathrm{T} 3$ = public defection.

\# Gambles A to $\mathrm{F}$ are ordered by increasing risk and expected value.

The reported standard errors are clustered at the villages/sessions level.

* coefficient significant at $10 \%$ level, $* *$ coefficient significant at $5 \%$ level, $* * *$ coefficient significant at $1 \%$ level. 


\section{Table 5: Choice of gamble in Round 2}

Dependent variable $=$ Gamble choice in Round 2 in an ordered probit: Gamble A is given a value of 1 , gamble $B$ a value of 2 , etc.

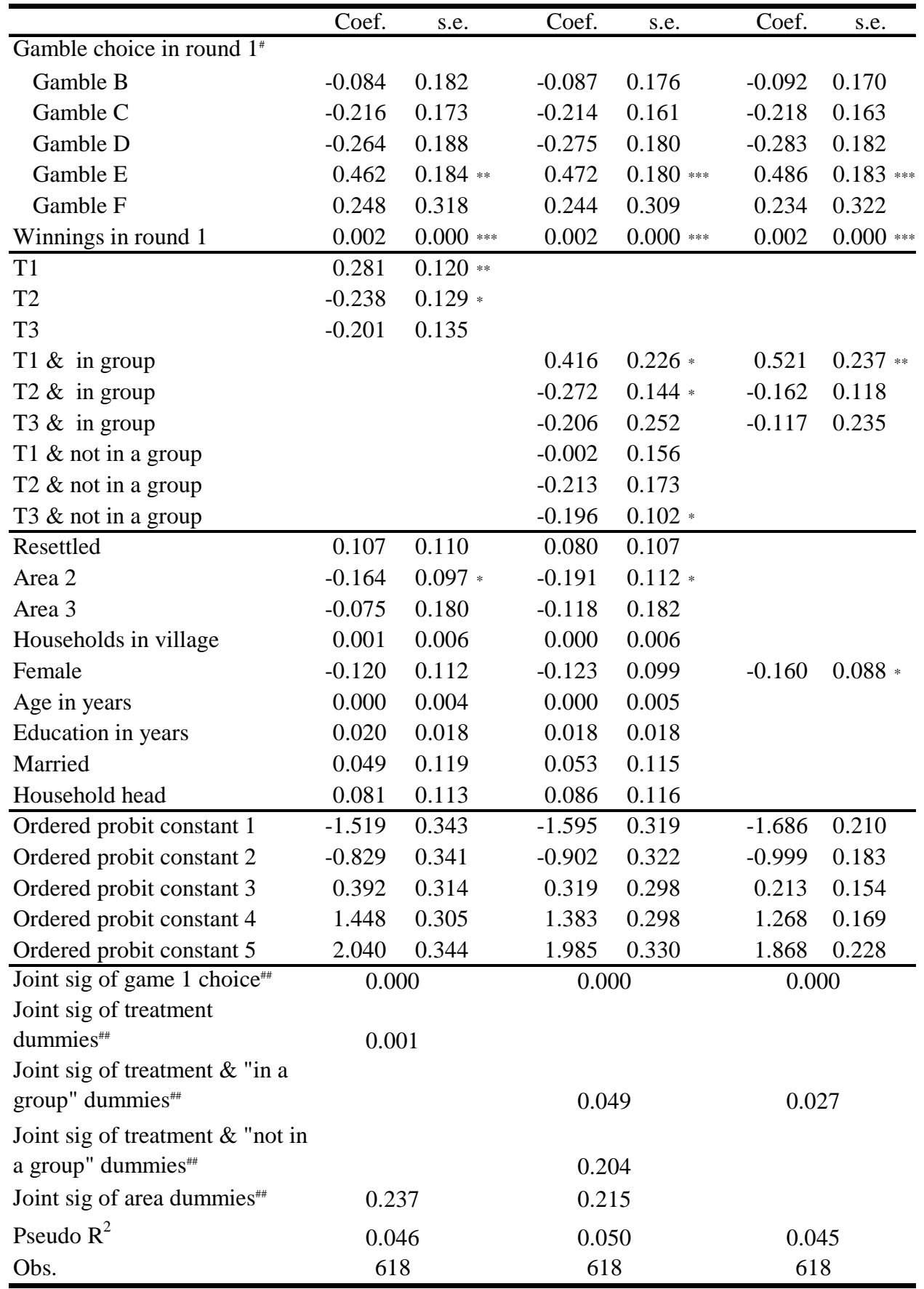

Notes: $\mathrm{C}$ = control; $\mathrm{T} 1$ = full commitment; $\mathrm{T} 2$ = private defection; $\mathrm{T} 3$ = public defection.

Gambles A to $\mathrm{F}$ are ordered by increasing risk and expected value.

Reported standard errors are clustered at the villages/sessions level.

* coefficient significant at $10 \%$ level, ** coefficient significant at $5 \%$ level, *** coefficient significant at $1 \%$ level.

\#\# P-value reported for joint significance of set of dummy variables. 


\section{Table 6: Correlations between experimental and real risk pooling networks}

\begin{tabular}{lcc}
\hline Village & $\begin{array}{c}\text { Significance of match between group formation and... } \\
\text { reported assistance } \\
\text { given }\end{array}$ & $\begin{array}{c}\text { reported assistance } \\
\text { received }\end{array}$ \\
\hline Pedzanhamo & $78.6 \%$ & $63.1 \%$ \\
Moturamhepo & $5.6 \%$ & $95.6 \%$ \\
Zvataida & $5.3 \%$ & $31.0 \%$ \\
Muringamombe & $15.1 \%$ & $9.9 \%$ \\
Mudzinge & $6.5 \%$ & $26.8 \%$ \\
\hline
\end{tabular}

Notes: Table reports P-values or significance levels in percentage form. The P-values relate to a series of non-parametric tests of the hypothesis that the groups that subjects form within the games bear some relation to the assistance networks they maintain in real life. Two tests were performed for each of the five named villages, one using the data on reported assistance given and one using the data on reported assistance received. 
Figure 1: Presentation of the gambles to the experimental subjects

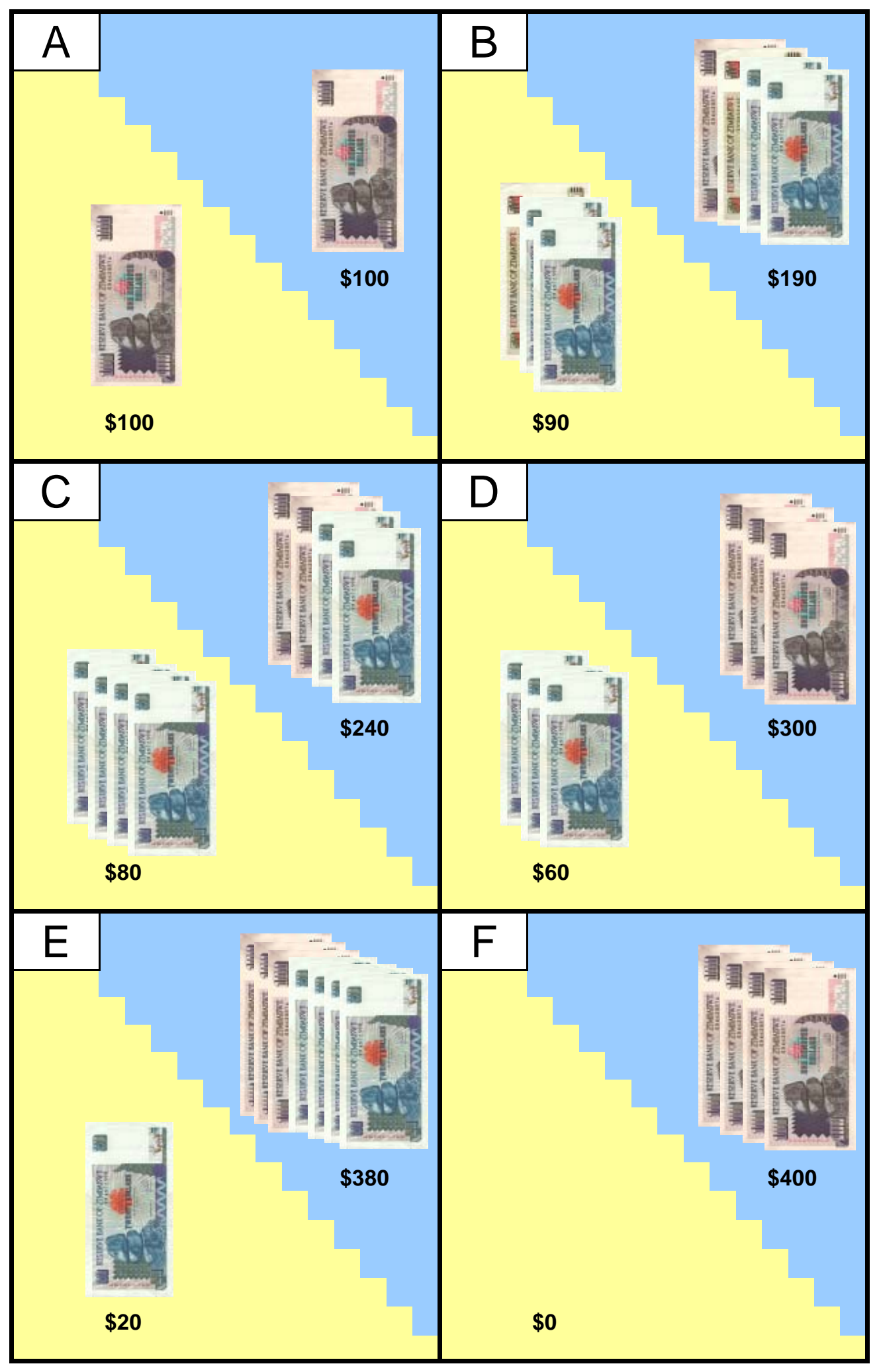




\section{Figure 2: Limited commitment and renegades} in Treatments $\mathrm{T} 2$ and $\mathrm{T} 3$
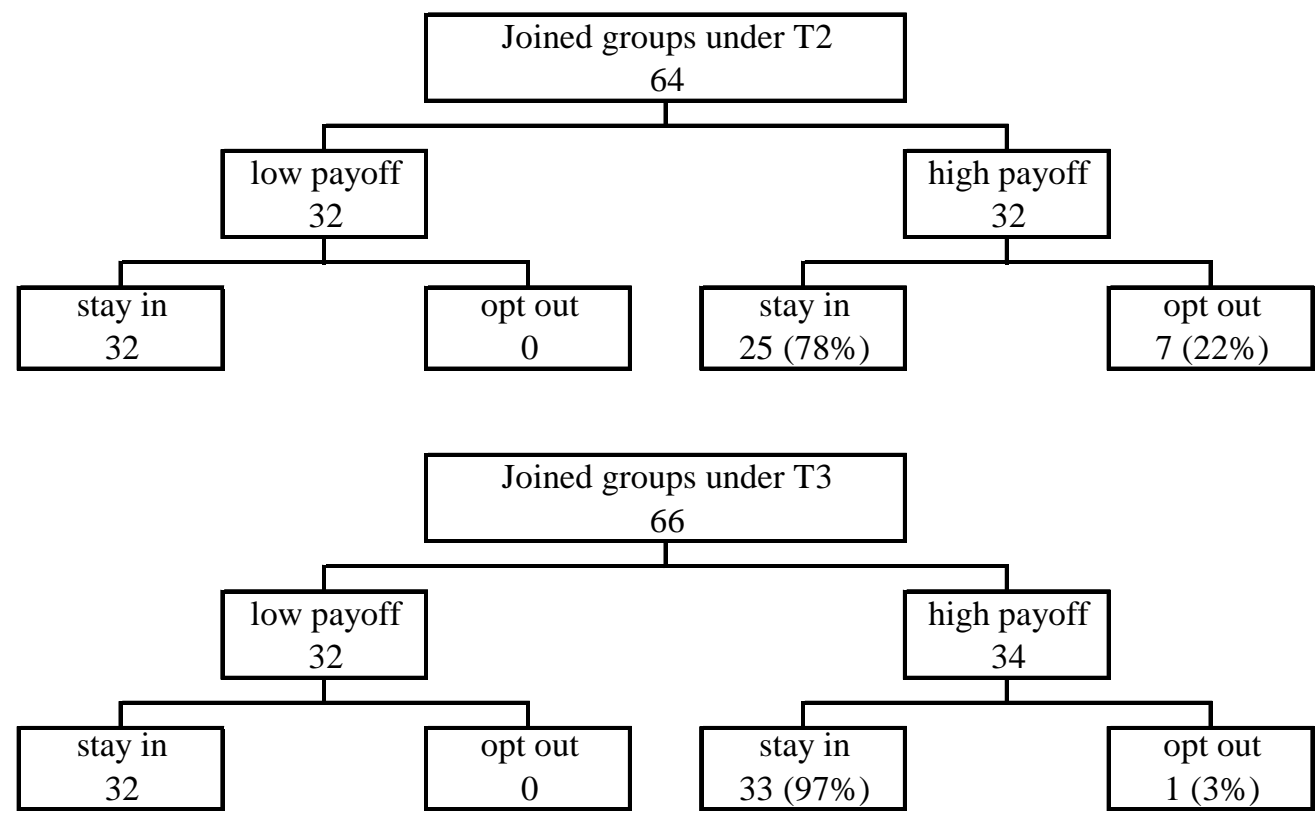

Notes: T2 = group formation with private defection; T3 = group formation with public defection. 
Figure 3: Group formation in second round of the risk pooling game

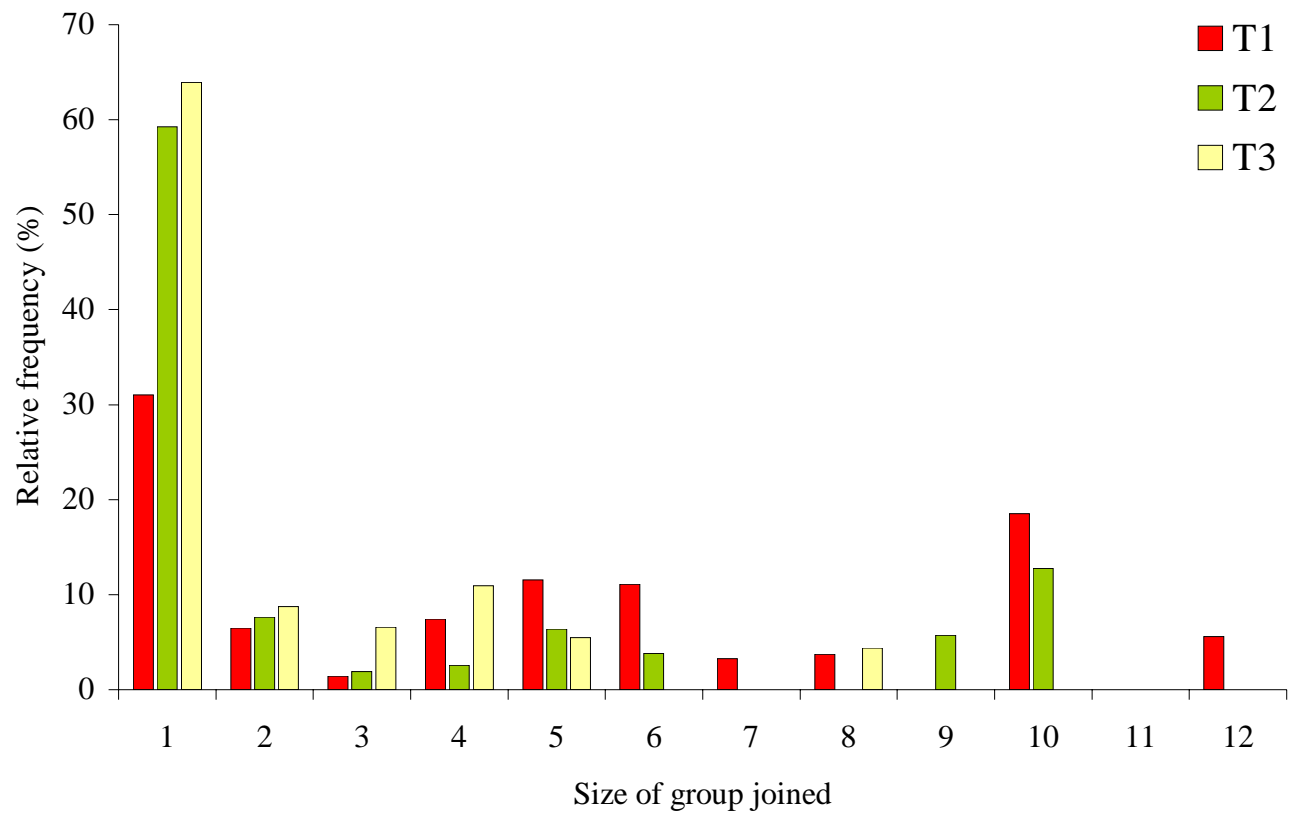

Notes: Only treatments where group formation is possible were considered.

$\mathrm{T} 1$ = full commitment; $\mathrm{T} 2$ = private defection; $\mathrm{T} 3$ = public defection.

A group size of 1 implies that the subject has either chosen to or has not been accepted into a group and was, thus, required to play solo in the second round. 
Figure 4: Choice of gamble in second round of the risk pooling game

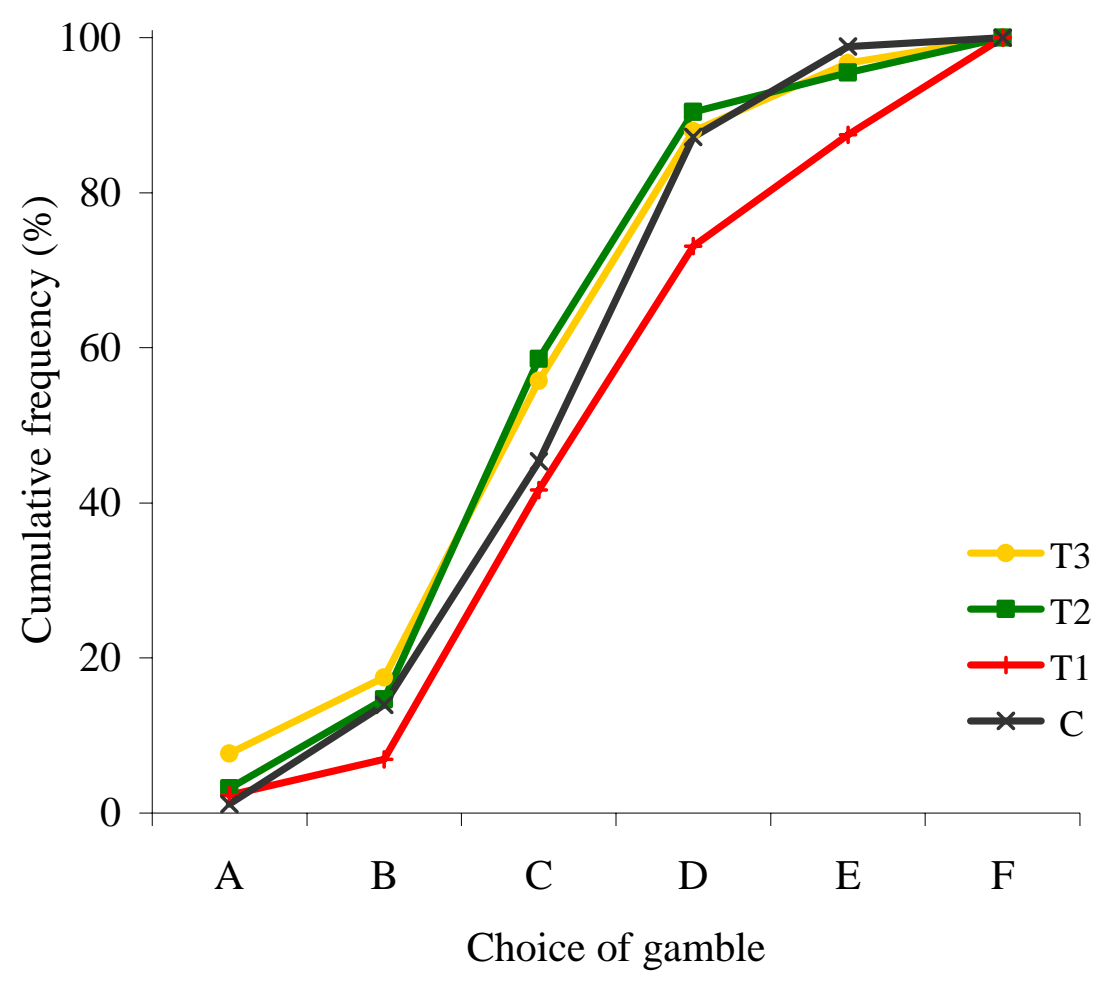

Notes: $\mathrm{C}=$ control; $\mathrm{T} 1$ = full commitment; $\mathrm{T} 2$ = private defection; $\mathrm{T} 3$ = public defection. Gambles A to F are ordered by increasing risk and expected value. 
Figure 5: Comparison of gambles chosen in first and second rounds

C

Gamble choice in round 2

\begin{tabular}{|c|c|c|c|c|c|c|c|c|}
\hline \multirow{6}{*}{ 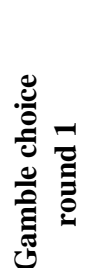 } & & A & B & C & D & $\mathbf{E}$ & $\mathbf{F}$ & Subs. \\
\hline & A & 0 & 20 & 20 & 40 & 20 & 0 & 10 \\
\hline & B & 0 & 13 & 27 & 53 & 7 & 0 & 15 \\
\hline & C & 0 & 8 & 42 & 46 & 4 & 0 & 24 \\
\hline & D & 3 & 14 & 31 & 34 & 14 & 3 & 29 \\
\hline & $\mathbf{E}$ & 0 & 0 & 0 & 50 & 50 & 0 & 2 \\
\hline & $\mathbf{F}$ & 0 & 17 & 33 & 33 & 17 & 0 & 6 \\
\hline
\end{tabular}

T2

Gamble choice in round 2

\begin{tabular}{|c|c|c|c|c|c|c|c|c|}
\hline \multirow{7}{*}{ 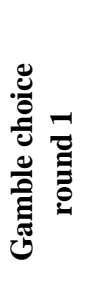 } & & A & B & C & D & $\mathbf{E}$ & $\mathbf{F}$ & Subs. \\
\hline & A & $\mathbf{0}$ & 6 & 50 & 28 & 6 & 11 & 18 \\
\hline & B & 5 & 19 & 38 & 29 & 5 & 5 & 21 \\
\hline & C & 0 & 10 & 51 & 36 & 3 & $\mathbf{0}$ & 39 \\
\hline & D & 5 & 16 & 39 & 30 & 5 & 4 & 56 \\
\hline & $\mathbf{E}$ & 0 & 0 & 38 & 38 & 13 & 13 & 8 \\
\hline & $\mathbf{F}$ & 11 & 0 & 33 & 33 & 11 & 11 & 9 \\
\hline
\end{tabular}

T1

Gamble choice in round 2

\begin{tabular}{|c|c|c|c|c|c|c|c|c|}
\hline \multirow{6}{*}{ 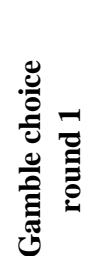 } & & A & B & C & D & $\mathbf{E}$ & $\mathbf{F}$ & Subs. \\
\hline & A & 18 & 12 & 12 & 18 & 12 & 29 & 17 \\
\hline & B & 0 & 0 & 41 & 27 & 14 & 18 & 22 \\
\hline & C & 1 & 6 & 40 & 31 & 13 & 9 & 80 \\
\hline & D & 1 & 4 & 37 & 37 & 14 & 7 & 73 \\
\hline & & $\mathbf{0}$ & 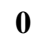 & 20 & 30 & 30 & 20 & 10 \\
\hline & & 0 & 0 & 0 & 38 & 13 & 0 & 8 \\
\hline
\end{tabular}

T3

Gamble choice in round 2

\begin{tabular}{|c|c|c|c|c|c|c|c|c|}
\hline \multirow{6}{*}{ 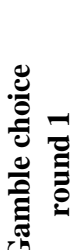 } & & A & B & C & D & E & $\mathbf{F}$ & Subs. \\
\hline & A & 20 & 10 & 15 & 45 & 5 & 5 & 20 \\
\hline & B & 8 & 16 & 24 & 40 & 8 & 4 & 25 \\
\hline & C & 4 & 4 & 53 & 28 & 7 & 5 & 57 \\
\hline & D & 6 & 13 & 43 & 28 & 11 & 0 & 54 \\
\hline & $\mathbf{E}$ & 0 & 0 & 20 & 60 & 20 & 0 & 10 \\
\hline & & 0 & 20 & 40 & 20 & $\mathbf{0}$ & 20 & 5 \\
\hline
\end{tabular}

Notes: Gambles A to F are ordered by increasing risk and expected value.

The numbers within the matrices are percentages. The $\mathrm{ij}^{\text {th }}$ element of a matrix is the percentage of those subjects who chose gamble $\mathrm{i}$ in the first round who went on to choose gamble $\mathrm{j}$ in the second round. The frequencies associated with the first round choices are shown in the columns to the right of the matrices. The cells of the matrices have been shaded in accordance with the percentage they contain; darker cells contain higher percentages.

\section{Figure 6: Comparison of gambles chosen in first round and second round under Treatment 2}

\section{T1 not in groups}

Gamble choice in round 2

\begin{tabular}{|c|c|c|c|c|c|c|c|c|}
\hline \multirow{7}{*}{ 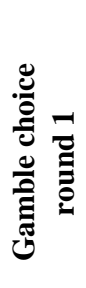 } & & A & B & C & D & $\mathbf{E}$ & $\mathbf{F}$ & Subs. \\
\hline & A & 33 & 0 & 17 & 33 & 0 & 17 & 6 \\
\hline & B & $\mathbf{0}$ & $\mathbf{0}$ & 57 & 43 & 0 & 0 & 7 \\
\hline & C & 0 & 4 & 48 & 33 & 15 & 0 & 27 \\
\hline & D & 6 & 6 & 28 & 50 & 11 & 0 & 18 \\
\hline & $\mathbf{E}$ & 0 & 0 & 50 & 25 & 0 & 25 & 4 \\
\hline & $\mathbf{F}$ & 0 & $\mathbf{0}$ & $\mathbf{0}$ & 50 & $\mathbf{0}$ & 50 & 2 \\
\hline
\end{tabular}

\section{T1 in groups}

Gamble choice in round 2

\begin{tabular}{|c|c|c|c|c|c|c|c|c|}
\hline \multirow{7}{*}{ 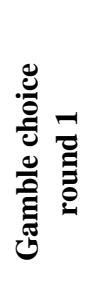 } & & A & B & C & D & $\mathbf{E}$ & $\mathbf{F}$ & Subs. \\
\hline & A & 9 & 18 & 9 & 9 & 18 & 36 & 11 \\
\hline & B & 0 & 0 & 33 & 20 & 20 & 27 & 15 \\
\hline & C & 2 & 8 & 36 & 30 & 11 & 13 & 53 \\
\hline & D & 0 & 4 & 40 & 33 & 15 & 9 & 55 \\
\hline & $\mathbf{E}$ & 0 & 0 & $\mathbf{0}$ & 33 & 50 & 17 & 6 \\
\hline & $\mathbf{F}$ & 0 & $\mathbf{0}$ & $\mathbf{0}$ & 33 & 17 & 50 & 6 \\
\hline
\end{tabular}

Notes: Gambles A to F are ordered by increasing risk and expected value.

The numbers within the matrices are percentages. The $\mathrm{ij}^{\text {th }}$ element of a matrix is the percentage of those subjects who chose gamble $i$ in the first round who went on to choose gamble $j$ in the second round. The frequencies associated with the first round choices are shown in the columns to the right of the matrices. The cells of the matrices have been shaded in accordance with the percentage they contain; darker cells contain higher percentages. 